\title{
Attitudes from mere co-occurrences are guided by differentiation
}

\author{
Hans Alves, Fabia Högden, Anne Gast, Frederik Aust and Christian Unkelbach \\ University of Cologne
}

\begin{abstract}
People often form attitudes about objects, individuals, or groups by examining and comparing their attributes. Such attribute-based attitude formation is guided by a differentiation principle: Whether people come to like or dislike an attitude object depends on the object's attributes that differentiate it from other objects. Attributes that are redundant with previously-encountered attitude objects are typically "cancelled" out. We tested whether the same differentiation principle applies to co-occurrence-based attitude formation, also known as Evaluative Conditioning. This form of attitude formation describes the phenomenon that attitudes are influenced by positive or negative stimuli that have co-occurred with the attitude object, but which are not inherent attributes of the attitude object itself. Across seven experiments $(\mathrm{N}=1611)$, we consistently found that co-occurrence-based attitude formation is guided by the same differentiation principle as attribute-based attitude formation. Specifically, participants' attitudes towards unknown brands were most strongly influenced by positive or negative stimuli that distinctly co-occurred with a specific brand, and that differentiated that brand from previously-encountered ones. Stimuli that redundantly co-occurred with multiple brands had weaker influences on brand attitudes. The results further suggest that differentiation operates at the learning stage during which distinct stimulus co-occurrences enjoy a processing advantage. We discuss the present findings' theoretical and practical implications for attitude formation and identify differentiation as a possible cause of biased attitudes.
\end{abstract}

Data, supplementary material: https://osf.io/eujs6/

One of the most fundamental questions addressed by social psychologists is how people form attitudes about objects, individuals, or groups, and how they come to like some of them more than others (Allport, 1935; Vogel \& Wänke, 2018). This question is of high relevance as attitudes guide behavior and determine whether people behave friendly or hostile towards others, whom they vote for, and what they spent their money on (Conrey \& Smith, 2007).

Typically, people form attitudes based on an attitude object's attributes. That is, people come to like attitude objects such as products, persons or groups whose attributes they like or find useful, and dislike attitude objects with negative attributes. This form of attitude

Hans Alves, Fabia Högden, Anne Gast, Frederik Aust, Chistian Unkelbach, Department of Psychology, University of Cologne.

The research was supported by an Emmy Noether grant from the Deutsche Forschungsgemeinschaft awarded to the third author (DFG; GA) and a grant awarded jointly to the third and fourth author (DFG; UN 273/4-2).

Correspondence concerning this paper should be addressed to Hans Alves, Department of Psychology, University of Cologne, Richard-Strauss-Str. 2, 50931 Köln, Germany. Email: hans.alves@uni-koeln.de. formation involves attribute learning and subsequent attribute integration into a summary evaluation (Asch, 1946; Anderson, 1965; Brewer, 1968; Fazio, 1989; Hogarth \& Einhorn, 1992). The algorithmic nature of this integration process has been extensively researched and debated (Anderson, 1971; 1981; Fishbein \& Ajzen, 1974; Fredrickson \& Kahneman, 1993); a common denominator though is that people weigh attributes differentially during integration. Some attributes influence the liking for an object, person, or group, more than others (e.g., Hogarth \& Einhorn, 1992).

A well-documented factor that influences attribute weighting is distinctiveness; that is, attributes that differentiate an attitude object from other objects influence people's attitudes most strongly. For example, whether a person is liked or disliked depends primarily on the person's distinct attributes and less on attributes that are shared with many others (e.g., Fiske, 1980; Wyer, 1974). Similarly, in choice formation, whether people come to like or dislike a choice option primarily depends on the options' distinct attributes that differentiate it from previously-encountered ones, while redundant attributes are canceled out (i.e., "cancellation" effects; e.g., De Bruin \& Keren, 2003; 
Hodges, 1997; Houston, Sherman, \& Baker, 1989, 1991).

While it is well-established that differentiation guides attribute-based attitude formation, it is unclear whether this principle also applies to other forms of attitude formation. Attitudes not always rely on explicit attribute learning; they can be based on the observation of co-occurrences in the environment, a phenomenon known as Evaluative Conditioning (Hofmann, De Houwer, Perugini, Baeyens, \& Crombez, 2010; De Houwer, 2007; Gast, Gawronski, \& De Houwer, 2012). Accordingly, attitudes towards objects, persons or groups are influenced by co-occurring positive or negative stimuli that are themselves not inherent attributes of the attitude object.

Evaluative Conditioning is regularly exploited in advertisements, where an attitude object such as brands or products are presented together with happy people, beautiful landscapes, or pleasant sounds. These are not inherent attributes of the product, but nevertheless positively influence consumers' attitudes (e.g., Allen \& Madden 1985; Gibson 2008; Sweldens, Van Osselaer, and Janiszewski, 2010). Likewise, attitudes towards persons or groups are also influenced by the mere presence of other stimuli such as other people or situational context stimuli (e.g., Baeyens, Eelen, van den Bergh, 1990; Fiedler \& Unkelbach, 2011; Olson \& Fazio, 2006). Evaluative Conditioning is regarded as a distinct form of attitude formation as the positive and negative stimuli or attributes do not need to relate to the attitude object or be inherent properties; rather, the mere co-occurrence suffices to shape resulting attitudes.

Despite extensive research on co-occurrence-based attitude formation, its broad applicability and apparent relevance (see Corneille \& Stahl, 2018; De Houwer, Thomas, \& Baeyens, 2001), the possibility that it is guided by a differentiation principle has not been addressed empirically nor theoretically. It is thus unknown whether stimuli that distinctly co-occur with a specific attitude object more strongly influence attitudes compared to stimuli that redundantly co-occur with multiple attitude objects. This is insofar surprising as such a differentiation principle would have substantial theoretical and practical implications. As we will discuss later, the prediction of a differentiation principle cannot be derived from common theoretical models of Evaluative Conditioning, and its existence would necessitate modifications or specification of these models. Practically, it would imply new ways to more effectively evoke and change people's attitudes towards brands and products, social groups, or healthy behavior. The present work therefore provides a systematic investigation in that regard and tests whether co-occurrence-based attitude formation (i.e., Evaluative Conditioning) is guided by the same differentiation principle as attribute-based attitude formation.

To anticipate the present research paradigm with a concrete example, consider a brand that co-occurs with different stimuli such as celebrities, sport events, or negative news headlines. Some of these stimuli may cooccur distinctly with this brand, others may (redundantly) co-occur with other brands as well. We seek to find out whether distinct and redundant cooccurrences exert a similar or differential influence on resulting brand attitudes.

In the following, we first introduce the differentiation principle in attitude formation in more detail and review empirical evidence from different domains. We then discuss the lack of theoretical and empirical insight regarding a differentiation principle in Evaluative Conditioning. Next, we present data from seven experiments in which we manipulated the distinctiveness of stimulus pairings and measured their influence on attitudes towards brands, and in which we gained several insights into the underlying cognitive processes. We close by discussing the differentiation principle's theoretical implications for explanations of Evaluative Conditioning and its practical implications for marketing and attitude change.

\section{Differentiation in Attribute-based Attitude Formation}

To illustrate the differentiation principle, Tversky's (1977) feature model of mental representations is wellsuited. Tversky (1977, p. 328) argued that people represent attitude objects such as faces, countries, or personalities in terms of many qualitative features or attributes, that can either be present or absent (see also Agostinelli, Sherman, Fazio, \& Hearst, 1986; McGill, 1989; Tversky \& Gati, 1982). Some attributes may be simultaneously present among different objects (i.e., redundant attributes) and others may be present in one object, but absent in another object (i.e., distinct attributes). Distinct attributes allow for differentiation and are indeed the "characterizing" attributes of an object, a person, or a group.

Consequently, distinct attributes are also the main driver of attitude formation, which prioritizes attributes that differentiate attitude objects from the population of objects. For example, impressions we form about a person are more strongly shaped by the person's distinct or rare behaviors and attributes that are not 
shared by many others (Alves, 2018; Bruner \& Perlmutter, 1957; Wyer, 1974). Fiske (1980) provided a rationale for this and argued that infrequent and thus distinct attributes or behaviors are more informative because they separate the attitude object from a larger part of the population.

Attitude formation also prioritizes attributes that differentiate an attitude object from other objects that occur in the same context. For example, in search for an apartment, people may browse different apartment options and read about their attributes such as price, location, and size. When people then compare the different options, they do not rely on all of the options' attributes equally, but focus on distinct features that differentiate among the options, while they "cancel out" redundant features (Hodges, 1997; Houston \& Sherman, 1995; Sanbonmatsu, Kardes, \& Gibson, 1991; Sherman, Houston, \& Eddy, 1999). This cancellation effect is sensitive to the temporal order in which different options are encountered. That is, preference judgments reflect attributes that differentiate the present option from previouslyencountered options, while attributes redundant with previously-encountered options are canceled out (Agostinelli et al., 1986; Alves, Koch, \& Unkelbach, 2018; Houston et al., 1989, 1991; Kardes \& Sanbonmatsu, 1993).

Similar to Fiske's (1980) idea of informativeness, cancellation may also serve the function of accounting for redundant information. Shared attributes do not allow to differentiate between options and thus do not allow to form preferences. Consequently, in choice formation, cancellation even constitutes a key axiom of expected utility theory (Neumann \& Morgenstern, 1944; Savage, 1954), and is thus regarded as a basic principle of rationality.

In sum, attitude formation based on attributes inherent in the attitude object is guided by differentiation. Yet, as stated above, attitude formation may also be based on the mere observation that an attitude object co-occurs with positive or negative stimuli, which are not inherent attributes of the object.

\section{Differentiation in Evaluative Conditioning}

In cognitive psychology, co-occurrence-based attitude formation is known as Evaluative Conditioning (Hofmann et al., 2010; De Houwer, 2007). Accordingly, the mere co-occurrence of a neutral stimulus (conditioned stimulus; CS) in spatiotemporal proximity to a positive or negative stimulus (unconditioned stimulus; US) suffices to create positive or negative attitudes toward the initially neutral stimulus (CS) (see Hofmann et al., 2010; for a metaanalysis). Even without information regarding the relation between the co-occurring stimuli (i.e., relational qualifiers), Evaluative Conditioning effects robustly occur. Evaluative conditioning is commonly regarded as a distinct form of attitude formation because it relies on the mere observations of stimulus co-occurrences. Whereas an attitude object's attributes are an integral part of the object itself, co-occurring stimuli are separable from the attitude object, and they need not be related to the attitude object in any way, but may simply co-occur by chance.

Because stimulus co-occurrences can be observed anywhere at any point in time Evaluative Conditioning as a form of attitude formation is relevant to any domain of attitude formation. For example, people's attitudes towards individuals or groups are influenced by merely co-occurring stimuli (Baeyens, eta 1., 1990; Baeyens, Eelen, Crombez, Van den Bergh, 1992; Koranyi, Gast, \& Rothermund, 2013; Olson \& Fazio, 2006; Walther, Nagengast, \& Trasseli, 2005). In our daily lives, we constantly meet or observe individuals or groups in different contexts such as the work place, specific neighborhoods, or we encounter them together with other individuals or groups, and these cooccurring stimuli shape our attitudes (Hughes, Ye, Van Dessel, \& De Houwer, 2018). As a result, individuals or groups may acquire the negativity of stigmatized groups they co-occur with (i.e., sins of the father effects; Pryor, Reeder, \& Monroe, 2012; Walther, 2002), or the messenger may acquire the message's negativity (i.e., kill-the-messenger effect, Walther et al., 2005). Interventions to reduce negative attitudes and implicit biases towards social groups also make use of co-occurrence-based procedures (e.g., Forscher et al., 2019; French, Franz, Phelan, \& Blaine, 2013).

Outside the social domain, Evaluative Conditioning has been applied to therapeutic and health-related domains (Houben, Schoenmakers, \& Wiers, 2010; Schienle, Stark, \& Vaitl, 2001), to consumer psychology (Gibson, 2008; Strick, van Baaren, Holland, \& van Knippenberg, 2009; Stuart, Shimp, \& Engle, 1987), and advertising (Förderer \& Unkelbach, 2011; Pleyers, Corneille, Yzerbyt, \& Luminet, 2009). Companies regularly exploit evaluative conditioning by presenting a brand or a product in the context of other positive stimuli to create a positive attitude within consumers (e.g., Gibson, 2008; Unkelbach \& Högden, 2019).

Distinct and Redundant Co-occurrences. Similar to attitude objects' attributes, which may be distinct or redundant, stimuli may distinctly or redundantly co- 
occur with and attitude object. For example, some positive or negative events in one's life may redundantly be accompanied by various individuals (e.g., when watching a football game), other experiences may be shared distinctly with specific individuals like a spouse (e.g., vacation). At the group level, some negative contexts in the media such as environmental problems may occur together with various social groups such as nations, other negative contexts such as the "refugee crisis" may co-occur rather distinctly with specific groups like "Syrians". Similarly, in advertisement, beautiful landscapes or happy people are frequently and redundantly used to elicit positive attitudes towards brands, specific celebrities, or unusual environments, on the other hand, constitute rather distinct stimuli that co-occur exclusively with one specific brand.

Even though stimulus co-occurrences in real life clearly differ regarding their distinctiveness, Evaluative Conditioning research has not address whether distinct and redundant co-occurrences have a similar impact on attitudes. More generally, there is little data on the question whether the differentiation principle that applies to attribute-based attitude formation also applies to co-occurrence-based attitude formation, and there is little to no theoretical consideration of this possibility. In the following, we review the limited available empirical and theoretical insights in that regard.

Research on Cue Competition. Empirically, the standard paradigm in Evaluative Conditioning research pairs pictures of attitude objects (CSs) with pictures of positive or negative stimuli (USs) (Levey \& Martin, 1975); these pairings are typically distinct; that is, a specific positive or negative picture is paired with one specific attitude object. Very few studies have tested what happens when different attitude objects "compete" for an association with the same positive or negative picture (US). This is surprising because socalled "cue competition" effects have led to major breakthroughs in research on Classical Conditioning (Pavlov, 1927) and related forms of predictor-outcome learning. For example, the discovery of cue competition effects resulted in influential learning theories such as the Rescorla-Wagner model (1972). Cue competition essentially describes phenomena where two predictor stimuli (e.g., bell sound and light) simultaneously co-occur with the same outcome stimulus (e.g., food); this predictor competition weakens the learned associations between each predictor and the outcome. Hence, for the case of predictor-outcome learning (e.g. Classical
Conditioning), whether an outcome is distinctly predicted by one cue or redundantly predicted by multiple cues clearly influences the learned associations.

Evaluative Conditioning on the other hand, is usually not considered a form of predictor-outcome learning (e.g., Baeyens, Hermans, \& Eelen, 1993; Baeyens, Crombez, Van den Bergh, \& Eelen 1988; De Houwer, Thomas, \& Baeyens, 2001; Gast, Langer, Sengewald, 2016), and the few studies that have addressed possible cue competition effects in this domain (see Beckers, de Vicq, \& Baeyens, 2009; Dwyer, Jarratt, \& Dick, 2007) have concluded that Evaluative Conditioning is not subject to cue competition effects (but see Walther, Ebert, Meinerling, 2011).

Theories of Evaluative Conditioning. The alleged absence of cue competition is often considered as a characteristic of Evaluative Conditioning that sets it apart from predictor-outcome learning such as Classical Conditioning (De Houwer et al., 2001). Cue competition effects require a sensitivity for stimulus contingencies that goes beyond the mere registration of stimulus contiguities. In that regard, associative theories of Evaluative Conditioning assume a primitive associative learning process that is sensitive to CS-US contiguities, but not to the pairing contingencies among different CSs and USs (Baeyens, et al., 1992; Baeyens, Vansteenwegen, Hermans, \& Eelen, 2001; De Houwer et al., 2001).

Insensitivity to contingencies is also assumed by an alternative theory that explains Evaluative Conditioning as implicit affective misattribution (Hütter \& Sweldens, 2013; March, Olson, \& Fazio, 2018; Jones, Fazio, \& Olson, 2009; Jones, Olson, \& Fazio, 2010). This theory argues that a positive or negative stimulus (US) evokes an affective response that is partially misattributed to the attitude object (CS) it is paired with. This misattribution process is insensitive to CS-US contingencies as "each cooccurrence is an opportunity for valence transfer" (Jones, Olson, \& Fazio, 2010; p. 222). From this perspective, distinctly and redundantly paired stimuli should exert a similar influence during attitude formation. Only if redundantly paired stimuli exerted a weaker affective response, the implicit misattribution account would predict a weaker influence on resulting attitudes. To the best of our knowledge, such an assumption has not been formulated.

Another perspective on Evaluative Conditioning argues that it reflects higher-order reasoning, that is, the generation and evaluation of propositions about CS-US 
relations (De Houwer, 2009, 2018; Unkelbach \& Fiedler, 2016; Mitchell, De Houwer, \& Lovibond, 2009). Accordingly, perceivers may infer from observing a co-occurrence of CS and US that these are somehow related and therefore of similar valence (De Houwer \& Hughes, 2016). This propositional account thereby suggests that co-occurrence-based attitude formation is subject to a similar inference process as attribute-based attitude formation. Therefore, it seems plausible that Evaluative Conditioning is guided by the same differentiation principle that guides attributebased attitude formation. However, while the differentiation principle would not violate the propositional account and could be predicted by it, until now this prediction has not been formulated.

\section{The Present Work}

The present work was motivated by the lack of empirical insight regarding the question whether cooccurrence-based attitude formation is guided by a differentiation principle. Given that stimulus cooccurrences in real life often differ regarding their distinctiveness, the answer to this question would have strong practical implications. And given that none of the existing theories on Evaluative Conditioning have formulated explicit predictions in that regard, a positive answer to this question would impose several constraints on available theories and may necessitate theoretical modifications and specifications.

Specifically, we tested whether attitudes about a given brand (CS) are primarily influenced by cooccurrences with valent (positive or negative) pictures (US) that differentiate the brand from previouslyencountered brands. The proposed differentiation principle can be further divided into two separate hypotheses.

First, distinctly paired US pictures (i.e., paired with only one brand) should influence brand evaluations more strongly compared with redundantly paired US pictures (i.e., paired with multiple brands). Second, this differential effect should interact with the brands' serial position during the learning sequence. Specifically, US pictures that differentiate a given CS brand from previously-encountered brands should have a particularly strong influence on brand evaluations. These two hypotheses are akin to typical "cancellation effects" in attribute-based attitude formation.

We tested these predictions in seven experiments. We determined sample sizes a priori for all experiments based on the following rule: In all experiments with one repeated measures factor and one between-participants factor (Exp. 1-4, 6, and 7), we aimed for a sample size of $N=200$, in order to obtain sufficient statistical power (> .80) to detect small-to-medium sized effects (Cohen, 1992). For Experiment 5, which included an additional between-participants factor, we doubled the desired sample size $(N=400)$. All data and stimuli can be retrieved

online

(https://osf.io/eujs6/?view_only=3edac6edbdb84accb4 81ddfe6154901d).

We conducted all experiments in our laboratory, located in the main building of a large university, which provides access to a pool of participants consisting of students from different subjects, as well as nonstudents. Nevertheless, because the majority of our participants are students, the subject sample can be considered a W.E.I.R.D. sample (Heinrich, Heine, \& Norenzayan, 2010). We do not consider this a severe problem for the present research, because the materials used (brand logos, and positive and negative pictures) are relatively culture independent. Specifically, the brand logos that we created consisted of simple designs and generic names that should not evoke a specific meaning depending on sociocultural context. Given that the positive and negative pictures were taken from the International Affective Pictures System, their subjective valence should also be relatively independent of sociocultural context. Regarding the psychological phenomenon that we are investigating here, which describes a basic principle of attitude formation, we also have no reason to believe that it should differ among different populations. Nevertheless, there remains some uncertainty regarding the generalizability of our empirical results to other participant populations and other stimuli, both CSs and USs.

\section{Experiment 1: Encountering Four Brands}

Experiment 1 constitutes our first test of the differentiation principle in Evaluative Conditioning. Specifically, we tested whether redundantly compared with distinctly paired US pictures differ regarding their influence on CS brand attitudes, and whether this difference is sensitive to the learning order. To test these predictions, we created a variant of an Evaluative Conditioning paradigm (see Figure 1) that adopts several characteristics of paradigms from choice formation that have led to the discovery of cancellation effects in attribute-based attitude formation (e.g., De Bruin \& Keren, 2003; Hodges, 1997; 2005; Houston et al., 1989, 1991). Experiment 1 consisted of four learning blocks, and in each block a CS brand was paired with two positive and two negative USs. After each block, participants evaluated the respective CS 
brand, before the next learning block began. There were two between-participants conditions. In the "negative distinct" condition, all negative US pictures were distinct, while all positive US pictures were redundant; that is, each brand was paired with unique negative images, while the positive images were the same across all brands. In the "positive distinct" condition, all positive US pictures were distinct, while all negative US pictures were redundant. We will refer to this experimental factor as "ecology", because it manipulates the evaluative information ecology that is presented to participants in the two conditions; that is, in one ecology positive information is distinct, while in the other ecology, negative information is distinct.

\section{Ecology}

$\begin{array}{ccccc} & \text { CS 1 } & \text { CS 2 } & \text { CS 3 } & \text { CS 4 } \\ \text { Negative Distinct } & \text { USpos1 } & \text { USpos1 } & \text { USpos1 } & \text { USpos1 } \\ & \text { USpos2 } & \text { USpos2 } & \text { USpos2 } & \text { USpos2 } \\ & \text { USneg1 } & \text { USneg3 } & \text { USneg5 } & \text { USneg7 } \\ & \text { USneg2 } & \text { USneg4 } & \text { USneg6 } & \text { USneg8 } \\ & & & & \\ & \text { CS 1 } & \text { CS 2 } & \text { CS 3 } & \text { CS 4 } \\ \text { Positive Distinct } & \text { USpos1 } & \text { USpos3 } & \text { USpos5 } & \text { USpos7 } \\ & \text { USpos2 } & \text { USpos4 } & \text { USpos6 } & \text { USpos8 } \\ & \text { USneg1 } & \text { USneg1 } & \text { USneg1 } & \text { USneg1 } \\ & \text { USneg2 } & \text { USneg2 } & \text { USneg2 } & \text { USneg2 }\end{array}$

Figure 1. Basic structure of the experimental paradigm. In four learning blocks, a given CS (brand) is sequentially paired with two positive and two negative USs (pictures). The conditions vary between participants whether positive or negative USs are distinctly paired (black) or redundantly paired (grey).

\section{Method}

Participants and design. We aimed at collecting data from 200 participants, and eventually collected data from 202 students (178 female, 24 male), who participated for course credit or candy. The serial position of the four CSs was manipulated within participants. The ecology factor varied between participants whether positive or negative USs were distinct or redundant (see Figure 1). The main dependent variable was participants' evaluations of the CS brands.

Procedure and Materials. Upon arriving in the laboratory, experimenters seated participants at individual work stations and started a Microsoft Visual Basic program. The program randomly selected $4 \mathrm{CS}$ brand logos from a pool of 8 logos created for the experiment. The program randomly determined which of the 4 CSs occurred in which learning block (i.e., serial position). The program also selected 10 IAPS pictures from a total of 16 IAPS pictures that served as USs and that were taken from the International Affective Picture System (IAPS) based on norm ratings regarding their pleasantness (Lang, Bradley, \&
Cuthbert, 1997). For the redundant pairings, the computer randomly selected two positive or two negative USs that were assigned to all CS brands. For the distinct pairings, the computer randomly assigned to each CS brand two of the eight available positive or negative USs.

Instructions informed participants about data confidentiality and about their right to quit the experiment at any point. After answering demographical questions, participants saw a standard EC instruction ("The following study investigates how people form impressions about brands. You will be presented with a series of picture pairings in which a brand logo always appears together with some other picture. Please follow the presentation carefully and try to form an impression about the brand."). The next screen informed participants to: "Please click on Continue to start the presentation". Then, the first learning block started. Each trial showed a CS brand alone in the top-center part of the screen for $1500 \mathrm{~ms}$. Next, the first US picture appeared below the CS brand and the CS-US pair was visible for $3000 \mathrm{~ms}$. This was repeated for all four US pictures. After the first CS brand was presented with all 4 USs that it was assigned 
to in random order, participants saw the following instruction "After you have formed an impression about the brand, we would now like you to evaluate the brand". On the next screen, participants were asked "How positive or negative is your impression of this brand?" Below the text, the brand logo was shown and below the logo was a rating scale ranging from 1 ("very negative") to 8 ("very positive"). After participants provided their rating, they were directed to another instruction screen ("Now we continue with another brand. You will again be presented with a series of picture pairings in which a brand logo always appears together with some other picture."). Participants then continued with the second learning block and the subsequent CS brand evaluation. The same procedure was repeated for the third and the fourth CS brand learning blocks. At the end of the experiment, the experimenter thanked, debriefed, and compensated participants.

\section{Results}

Figure 2 shows participants' mean brand evaluations as a function of serial position (first to fourth position) and ecology (negative distinct or positive distinct). To analyze these data, we specified a general linear model that predicted brand evaluations by the repeated factor position, the betweenparticipants factor ecology, and their interaction. In addition, we specified two kinds of planned contrasts. First, we specified simple contrasts comparing each position with the first position. Second, we specified polynomial contrast to test for a possible linear or quadratic interaction between position and ecology.

The analysis revealed a main effect of ecology, $F(1$, $200)=8.83, p=.003, \eta_{p}{ }^{2}=.04$. As Figure 2 shows, CS brands were overall evaluated more positively in the positive distinct ecology than in the negative distinct ecology, providing evidence for an overall stronger influence of distinct compared to redundant US pairings. This main effect was qualified by an interaction of ecology and position $F(3,600)=7.62, p$ $<.001, \eta_{p}{ }^{2}=.04$. Planned simple contrasts showed that this interaction was significant for all three comparisons when evaluations of CS2, CS3, and CS4 were compared to those of CS1 (2 vs 1: $F(1,200)=$ 23.01, $p<.001, \eta_{p}{ }^{2}=.10 ; 3$ vs $1: F(1,200)=15.55, p$ $<.001, \eta_{p}{ }^{2}=.07 ; 4$ vs. $1: F(1,200)=9.09, p=.003, \eta_{p}{ }^{2}$ $=.04)$.

Hence, results show a clear interaction between ecology and serial position. That is, the stronger impact of distinctly paired USs did not apply to evaluations of the first brand, but only to later-encountered brands. It seems that the stronger impact of distinct pairings then decreased from position 2 to position 4 , as the interaction more closely followed a quadratic than a linear trend (Quadratic: $F(1,200)=13.91, p<.001, \eta_{p}{ }^{2}$ $=.07$., linear: $\left.F(1,200)=8.12, p=.005, \eta_{p}{ }^{2}=.04\right)$.

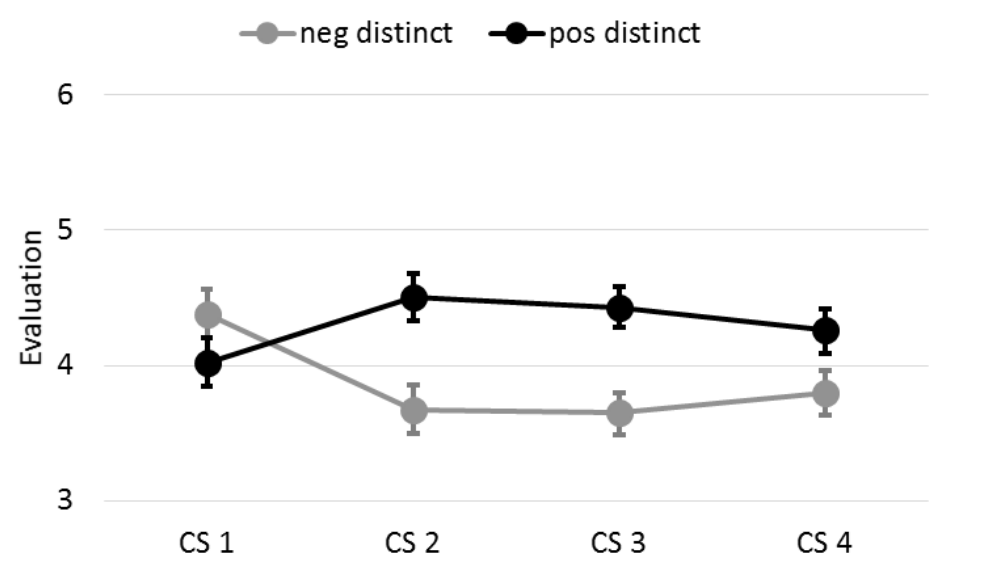

Figure 2. Mean evaluations of the four CSs brands as a function of their serial position in the negative distinct and in the positive distinct ecologies. Error bars represent standard errors of the means.

\section{Discussion}

Experiment 1 provided first evidence for the idea that Evaluative Conditioning follows a differentiation principle. While participants evaluated the first CS brand in the learning sequence as roughly neutral (scale mid-point $=4.5$ ), evaluations of the subsequent brands were influenced by the ecology factor. That is, the valence of distinctly-paired US pictures influenced evaluations more strongly. Accordingly, in an information ecology with positive redundancy and negative distinctiveness, later occurring attitude objects 
are evaluated less favorably, while the reverse is true in an information ecology with negative redundancy and positive distinctiveness.

Next, we tested in Experiment 2 whether the effect relies on the immediate evaluation of a given brand after its respective learning block (i.e., sequential evaluation). This may be the case, because when participants evaluate the first CS brand, they do not know which US pictures will later be redundant with subsequent CS brands. Yet, in attribute-based attitude formation, the differentiation principle occurs even when all attitude objects are evaluated at the end of the whole learning sequence (e.g., De Bruin \& Keren, 2003; see also Unkelbach \& Memmert, 2014). Thus, the next experiment asked participants to evaluate the CS brands after all 4 learning blocks (i.e., end-ofsequence judgments).

\section{Experiment 2: End-of-Sequence Judgments}

Experiment 2 resembled Experiment 1 with one exception. Instead of evaluating each CS brand after its respective learning block, participants evaluated all 4 brands after they had completed all 4 learning blocks.

\section{Methods}

Participants and design. We again aimed at collecting data from 200 participants, and eventually collected data from 202 students of a large university (158 female, 44 male), who participated for course credit or candy.

Procedure and Materials. The experimental procedure was highly similar to Experiment 1 except that participants evaluated the CS brands after all four learning blocks. The order of the four CS brand evaluations was identical to the order of the four learning blocks. That is, participants were first asked to evaluate CS1, then CS2, then CS3, and finally CS4 (see Figure 1). At the end, the experimenter thanked, debriefed, and compensated participants.

\section{Results}

Figure 3 shows participants' mean CS brand evaluations as a function of serial position and ecology. We used the same general linear model and planned contrasts as in Experiment 1 to analyze these data. The analysis again revealed a main effect of condition, which was considerably larger than in the first experiment, $F(1,200)=24.79, p<.001, \eta_{p}{ }^{2}=.11$. As illustrated in Figure 3, overall, brands were evaluated more positively in the positive distinct ecology compared with the negative distinct ecology. This main effect was again qualified by an interaction between ecology and position $F(3,600)=9.15, p<.001, \eta_{p}{ }^{2}=$ .04. Planned simple contrasts showed that this interaction was significant for all three comparisons when evaluations of $\mathrm{CS} 2, \mathrm{CS} 3$, and $\mathrm{CS} 4$ were compared to CS1 $\left(2\right.$ vs $1: F(1,200)=6.70, p=.01, \eta_{p}{ }^{2}$ $=.03 ; 3$ vs $1: F(1,200)=23.68, p<.001, \eta_{p}{ }^{2}=.10 ; 4$ vs. $\left.1: F(1,200)=15.68, p<.001, \eta_{p}{ }^{2}=.07\right)$. As Figure 3 shows, the interaction more closely followed a linear rather than a quadratic trend (Linear: $F(1,200)=18.66$, $p<.001, \eta_{p}{ }^{2}=.09$, quadratic: $F(1,200)=5.56, p=.019$, $\left.\eta_{p}^{2}=.03\right)$.

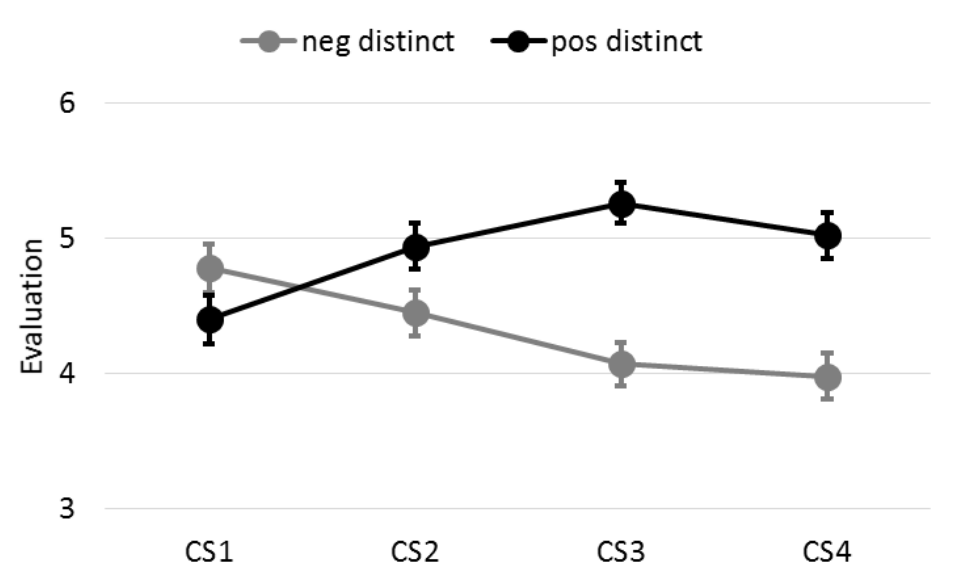

Figure 3. Mean evaluations of the four CSs brands as a function of their serial position in the negative distinct and in the positive distinct ecologies. Error bars represent standard errors of the means. 


\section{Discussion}

Experiment 2 confirmed that Evaluative Conditioning follows a differentiation principle. Overall, the valence of the distinctly paired US pictures compared to the redundantly paired US pictures influenced brand evaluations more strongly, visible in the ecology main effect. This stronger influence was again sensitive to the temporal learning order, visible in the contrast analyses. In the negative distinct ecology, participants judged the first CS brand as more positive than the subsequent brands, while the reverse was true in the positive distinct ecology. Crucially, this effect occurred even though participants provided brand evaluations after all learning blocks. Hence, while participants were given the chance to learn that redundant US pictures were redundant among all CS brands, including CS 1, their evaluations of CS 1 were not affected by this redundancy. Instead, evaluations of CS 1 were close to the 4.5 midpoint of the scale. Redundancy, however, affected the evaluation of the subsequent CS brands. In addition, the differential effect of distinct and redundant US pictures increased for later encountered brands as indicated by the linear trend. It appears that the more brands a US picture is paired with, the weaker its influence on evaluations of subsequent brands.

Experiment 1 and 2 are thus in line with the prediction that co-occurrence-based attitudes are more strongly influenced by distinctly compared with redundantly paired USs pictures, and this influence is sensitive to the learning order. In other words, Evaluative Conditioning seems to follows a differentiation principle.

An alternative explanation for the observed pattern is that repeated exposure to the redundant US pictures reduces their affective value. That is, repetition could give rise to adaptation or habituation and result in diminished affective potential of the US (e.g., Hammerl, Bloch, \& Silverthorne, 1997; Randich \& LoLordo, 1979). For example, when a participant is exposed to a negative picture for the first time, the picture may elicit strong negative affect which is then transferred to the CS brand, while this affective potential may decrease when the same US picture is encountered repeatedly. While recent research found that repeated exposure to stimuli increases and not decreases subjective affective intensity of stimuli (Mrkva \& Van Boven, 2020), it is nevertheless important to test a possible habituation explanation. Experiment 3 therefore aimed to replicate Experiment 2 and also asked participants to evaluate the US pictures at the end of the experiment.

\section{Experiment 3: Affective Fading?}

Experiment 3 procedurally replicated Experiment 2 as participants were asked to evaluate the brands at the end of all learning blocks. In addition, Experiment 3 tested whether the previous findings could be explained by a reduced affective potential among redundant US pictures. Hence, after the conditioning procedure, participants were asked to evaluate the US pictures. If diminished affective potential of redundant US pictures explains the previous effects, they should be evaluated as less positive and less negative compared to the distinct US pictures of the same valence.

\section{Methods}

Participants and design. We collected data from 200 students of a large university (144 female, 56 male) who participated for course credit or candy. The experimental design included the same factors as Experiments 1 and 2. The main dependent variable was again participants' explicit CS brand evaluations, but participants also provided US picture evaluations at the end of the experiment.

Procedure and Materials. The experimental procedure was similar to Experiments 1 and 2, but added US picture evaluations at the end of the experiment. Experiment 3 also asked participants to indicate for each CS brand, which US picture it had occurred with. We do not report data from this task here, but participants' responses can be found in the data sets that are available online (https://osf.io/eujs6/?view_only=3edac6edbdb84accb4 81ddfe6154901d) ${ }^{1}$. Next, participants proceeded to the US picture evaluation task which presented each US picture in randomized order and asked participants to rate the valence of the picture on a scale from 1 ("very negative") to 8 ("very positive"). At the end, the experimenter thanked, debriefed, and compensated participants.

\section{Results}

CS Brand Evaluation. Figure 4 presents participants' mean CS brand evaluations. We specified the same general linear model and planned contrasts as in the previous experiments to analyze this data. The analysis again found a main effect of ecology, $F(1,198)$ $=9.51, p=.002, \eta_{p}{ }^{2}=.05$. As Figure 4 shows, CS brands were evaluated more positively when the positive pairings were distinct compared to when the negative pairings were distinct. This main effect was again qualified by an interaction between ecology and position $F(3,594)=6.97, p<.001, \eta_{p}{ }^{2}=.03$. Planned 
simple contrasts showed that this interaction was significant for all three comparisons when CS2, CS3, and CS4 were compared to CS1 (2 vs 1: $F(1,198)=$ 4.70, $p=.031, \eta_{p}{ }^{2}=.02 ; 3$ vs $1: F(1,198)=11.80, p=$ $.001, \eta_{p}{ }^{2}=.06 ; 4$ vs. $1: F(1,198)=18.47, p<.001, \eta_{p}{ }^{2}$
$=.09)$. As Figure 4 illustrates, the interaction followed a linear trend, $F(1,198)=19.75, p<.001, \eta_{p}{ }^{2}=.09$, and not a quadratic trend, $F(1,198)=0.60, p=.442$, $\eta_{p}{ }^{2}=.003$

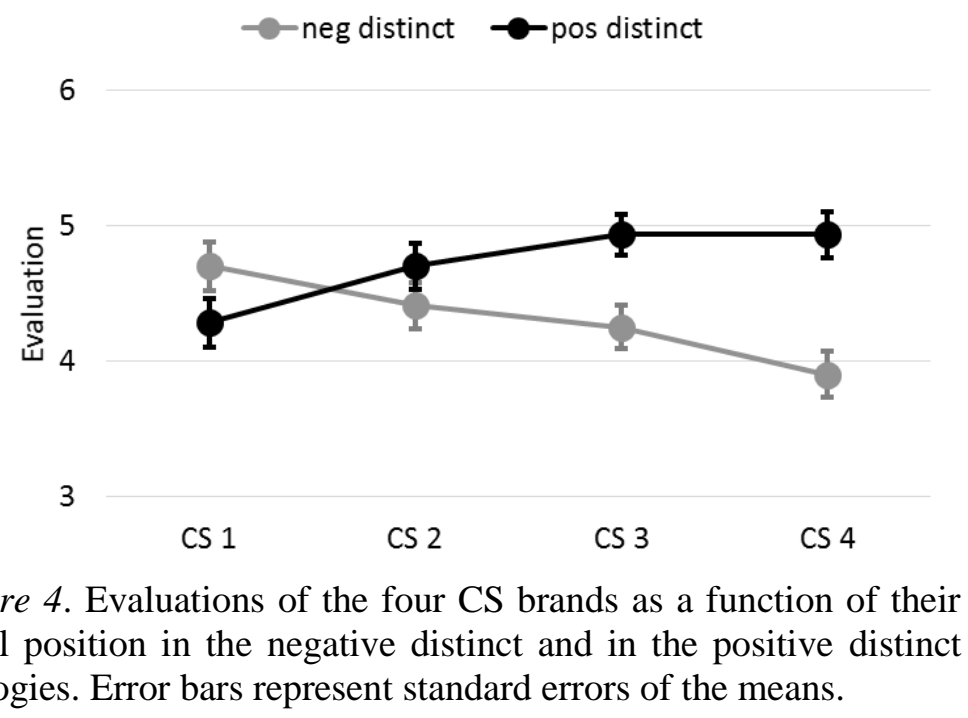

US Picture Evaluation. We then tested whether redundant US pictures had a weaker affective potential compared with distinct US pictures by comparing the evaluative ratings of distinct and redundant USs. If redundant US pictures lose their affective potential, then participants' evaluative ratings for these redundant USs should be less extreme. For each participant, we thus calculated mean evaluations for the positive USs and for the negative USs. We specified a general linear model with the repeated-measures factor US valence and ecology as a between participants factor. In this analysis, weaker (stronger) affective potential of redundant (distinct) USs should appear as an ecology main effect.

Unsurprisingly, this analysis revealed a significant main effect of US valence, $F(1,198)=2961.88 p<$ $.001, \eta_{p}{ }^{2}=.94$. Participants evaluated the positive USs more positively than the negative USs. The ecology main effect was also significant, $F(1,198)=49.49, p<$ $.001, \eta_{p}{ }^{2}=.20$. However, this effect was opposite to the direction predicted by a diminished affective potential explanation. Participants evaluated US pictures from both valences as more extreme when they were redundant. Specifically, they rated redundantly paired positive USs as more positive $(M=7.29, S D=0.82)$ compared to distinctly paired positive USs $(M=6.85$, $S D=0.70), t(198)=4.07, p<.001, d=.58$. Likewise, participants rated redundantly paired negative USs as more negative $(M=1.75, S D=0.97)$ compared to distinctly paired negative USs $(M=2.27, S D=0.76)$, $t(198)=4.30, p<.001, d=.60$. Hence, repeated exposure to US pictures seems to amplify their affective potential, rather than weaken it. The interaction between US valence and ecology was not significant, $F(1,198)=0.24, p=.624, \eta_{p}^{2}=.001$.

\section{Discussion}

Experiment 3 provided further support for the differentiation principle. We replicated the main pattern: When negative US pictures were distinct, participants again evaluated the first CS brand more positively than the subsequent brands, while they evaluated the first CS brand more negatively when positive US pictures were distinct.

In addition, Experiment 3 rendered a potential affective fading explanation unlikely. Contrary to the idea that repeatedly encountered pictured may lose their affective potential, their affective potential seemed to have increased; in other words, we observed evaluative sensitization rather than evaluative adaptation. While this finding is well in line with recent empirical investigation on the effects of repeated exposure on affective extremity (Mrka $\&$ van Boven, 2020), it makes the present differential influence of redundant and distinct US pictures on CS brand evaluations even more remarkable. Pairing the same US picture with multiple CS brands seems to increase its affective potential, but decreases its influence on CS 
brand evaluations. Yet, it has to be noted that one may question whether explicit evaluations of US pictures are well-suited to capture affective fading, an argument that we will come back to later.

We first turn to the question whether the differentiation principle exerts its influence at the learning stage or at the judgment stage. One possibility is that distinctly paired USs enjoy a processing advantage so that they exert a stronger influence during attitude formation. Another possibility is that distinctly and redundantly paired US pictures exert the same influence during learning, but when participants evaluate the brands, they may engage in comparative judgments and evaluate a given CS brand based on how it is different from the previously-evaluated brand. Crucially, in the previous experiments, the order of the CS brands at the evaluation stage always corresponded to their learning order. Hence, the present effects may be a function of judgment order, rather than of learning order. We address this possibility in the following Experiment 4, which randomized the order of the CS brands during the evaluation stage, and allows to test whether the stronger influence of distinct compared to redundant pairings was a function of learning order or of judgment order.

\section{Experiment 4: Randomized Evaluation Order}

Experiment 4 was similar to Experiment 3 but randomized the evaluation order of the CS brands.

\section{Methods}

Participants and design. We collected data from 202 students (148 female, 54 male), who participated for course credit or candy. The design was identical to Experiments 1 to 3 . The main dependent variable was participants' CS brand evaluations; in addition, participants again evaluated the US pictures at the end.

Procedure and Materials. Procedures and materials were highly similar to Experiment 3 except that the order of the four CS evaluations was randomized $^{2}$. At the end, the experimenter thanked, debriefed, and compensated participants.

\section{Results}

CS Brand Evaluation. Figure 5 presents the data pattern, which we analyzed using the same general linear model as in the previous experiments. The analysis again found a main effect of ecology, $F(1,200)$ $=15.88, p<.001, \eta_{p}{ }^{2}=.07$. As illustrated in Figure 5, CS brands were evaluated more positively when the positive pairings were distinct, compared to when the negative pairings were distinct. This main effect was again qualified by an interaction between ecology and learning position $F(3,600)=3.09, p=.027, \eta_{p}{ }^{2}=.02$, which was somewhat smaller than in the previous experiments. Planned simple contrasts between CS1 and the following stimuli showed that this interaction was not significant for CS2, but for CS3 and CS4, when these were compared to CS1 (2 vs 1: $F(1,200)=1.70$, $p=.194, \eta_{p}{ }^{2}=.01 ; 3$ vs $1: F(1,200)=5.98, p=.015$, $\eta_{p}{ }^{2}=.06 ; 4$ vs. $\left.1: F(1,200)=6.51, p=.011, \eta_{p}{ }^{2}=.03\right)$. As Figure 5 shows, the interaction again followed a linear trend, $F(1,200)=7.28, p=.008, \eta_{p}{ }^{2}=.04$, while the quadratic trend was non-significant, $F(1,200)=$ $0.87, p=.352, \eta_{p}{ }^{2}=.004$.

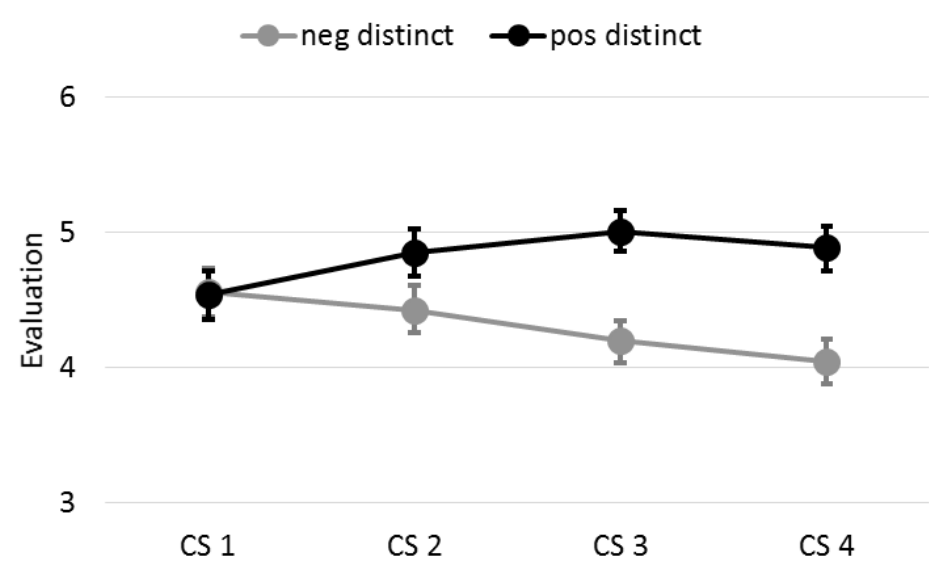

Figure 5. Evaluations of the four CS brands as a function of their serial learning position in the negative distinct and in the positive distinct ecologies. Error bars represent standard errors of the means. 
We then repeated the same analysis, but exchanged the repeated factor serial learning position with serial judgment position. Hence, we tested whether the order in which participants evaluated the CS brands also influenced their evaluations. While the ecology main effect obviously remained unchanged, this main effect did not interact with judgment position, $F(3,600)=$ $0.80, p=.495$.

US Picture Evaluation. For each participant, we again calculated mean evaluations for the positive and negative US pictures. We specified a general linear model with the repeated measures factor US valence and ecology as a between participants factor. This analysis again showed a significant main effect of US valence, $F(1,200)=2207.48 p<.001, \eta_{p}{ }^{2}=.92$, as the positive USs were evaluated more positively than the negative USs. The main effect of ecology was also significant, $F(1,200)=34.32, p<.001, \eta_{p}{ }^{2}=.15$. As in Experiment 3, participants evaluated the redundantly paired positive USs more positively $(M=7.22, S D=$ $0.95)$ compared to the distinctly paired positive USs ( $M$ $=6.87, S D=0.85), t(200)=2.72, p=.007, \mathrm{~d}=.39$. Likewise, participants evaluated the redundantly paired negative USs more negatively $(M=1.82, S D=1.01)$ compared with the distinctly paired negative USs $(M=$ 2.23, $S D=0.72), t(200)=3.33, p=.001, \mathrm{~d}=.47$, Hence, repeated exposure to US pictures again strengthened their affective potential instead of weakened it. The interaction between US valence and ecology was not significant, $F(1,200)=0.09, p=.759$, $\eta_{p}{ }^{2}=.0005$.

\section{Discussion}

Experiment 4 replicated the differentiation principle when CS brand evaluation order was randomized. The effect was smaller than in the previous experiments, but nevertheless consistent. The randomized CS brand judgment order most likely added noise to the effects. Yet, this noise was unsystematic and provided no support for differentiation as a function of judgment order. As Figure 5 illustrates, participants evaluated the CS brands in the positive distinct ecology more positively than CS brands in the negative distinct ecology, and this effect depended on learning order, but not on judgment order. These findings suggest that the differentiation principle guides the formation of attitudes during the learning stage. In addition, and as in the previous experiment, the weaker overall impact of redundant US pictures again stood in contrast to their stronger evaluative potential as indicated by participants' US picture evaluations.
Next, we aimed to further investigate the processes underlying the observed data pattern. While Experiment 4 showed that differentiation is sensitive to the learning but not the judgment order, it is still not clear whether it constitutes a true learning effect or a judgment effect. One possibility is that distinct and redundant stimulus pairings have a differential impact on learning, depending on the serial position of the brands. That is, CS-US pairings that differentiate the present CS brand from previously-encountered CS brands may have a processing advantage during learning over redundant pairings which results in stronger memory traces. Alternatively, learning of distinct and redundant pairings may be equally strong, but perceivers denote differential weights to them when evaluating the brands.

Experiment 5 will address the question whether the differentiation principle follows from differential learning or differential weighting. In this experiment, we assessed the pairing contingencies that participants had learned during the conditioning phase, by asking them to recall how many times each brand was paired with positive and negative pictures (Stahl, Unkelbach, \& Corneille, 2009).

In addition, Experiment 5 tested a possible boundary condition of the differentiation principle, namely participants' processing goals. Note that all previous experiments used an "impression formation" instruction, telling participants to form impressions about the brands. Possibly, this instruction let participants reason that the US pictures constituted some kind of attributes that describe the brands that they co-occur with. In line with this idea, previous research on processing goals in Evaluative Conditioning showed that an impression formation goal indeed increases sensitivity to information that specifies the relation between a CS and US (Moran, Bar-Anan, \& Nosek, 2015). A goal to merely remember the CS-US pairings on the other hand increased sensitivity to mere associative information. Hence, the impression formation instruction that we have used in the previous experiments may have let participants to treat the co-occurring US pictures as attributes of the brands, which may have given rise to attribute-based attitude formation. To test whether differentiation also guides the formation of co-occurrence based attitudes in absence of an impression formation goal, the following Experiment 5 introduced a new condition in which participants were mere instructed to memorize all stimulus pairings. 
Experiment 5: Differential learning vs. differential weighing

Experiment 5 tested whether differentiation as visible in the brand evaluations is due to differential learning or differential weighing of distinct versus redundant co-occurrences. After the conditioning phase and after participants had evaluated all four brands, they were asked to recall the pairing contingencies. For each brand, participants were asked to recall the number of times the brand had co-occurred with a positive and the number of times it had co-occurred with a negative picture. If the differentiation principle guides learning, participants should overestimate the number of distinct relative to redundant pairings, especially for later-encountered brands. However, if participants are able to accurately reproduce the pairing frequencies, this would suggest that differentiation does not affect learning but merely the weighing of pairings during evaluation. Experiment 5 also added another between-participants condition that did not instruct participants to form an impression about the brands but merely to memorize the pairings (Moran, Bar-Anan, \& Nosek, 2015). This condition served to test whether differentiation also guides co-occurrence based attitude formation in absence of an impression formation goal, which may give rise to an attributebased attitude formation process.

\section{Methods}

Participants and design. Compared to Experiments 1-4, Experiment 5 included an additional between-subjects factor that varied the instructions (impression formation vs. memory task). We doubled the desired sample size and aimed for 400 participants. We ended up collecting data from 408 students of a large university (247 female, 161 male), who participated for course credit or candy. The design of Experiment 5 was similar to the previous Experiment 4, except that two between-subjects conditions varied whether participants received an impression formation instruction or a memory task instruction prior to encountering the brands and the IAPS pictures.

Procedure and Materials. The procedure was similar to that of the previous experiments except that participants received one of two different instructions at the beginning of the experiment. The impression formation condition was similar to the previous experiments and instructed participants to from impressions about different brands that would be presented together with different pictures. The memory task condition instructed participants that they would be presented with different brand logos along with pictures, and that their task was to "detect any regularities and to remember them". Participants were also informed that they would be asked questions about the picture pairings later.

After the pairings, participants in both conditions were again asked to evaluate all four brands. Similar to Experiments 1-4, brand evaluation order was again identical to the learning order. Next, participants were asked to recall the pairing contingencies. Specifically, they were instructed to recall "how often each of the brands occurred together with a positive picture, and how often it occurred together with a negative picture". Participants were then sequentially presented with all four brands along with text boxes, and for each brand they were asked to provide the number times this brand had occurred together with a positive (negative) picture. The order of the brands was identical to the learning order. At the end, the experimenter thanked, debriefed, and compensated participants.

\section{Results}

CS Brand Evaluation. We specified a general linear model including the factors ecology (betweensubjects), instruction (between-subjects), and position (within-subjects). Similar to the previous experiments, the analysis found a significant main effect of ecology, $F(1,404)=32.21, p<.001, \eta_{p}{ }^{2}=.07$. As illustrated in Figure 6, overall, brands were evaluated more positively in the positive distinct ecology, but more negatively in the negative distinct ecology. This main effect was again qualified by an interaction with position $F(3,1212)=20.17, p<.001, \eta_{p}{ }^{2}=.05$. This interaction did not depend on the type of instruction that participants received $F(3,1212)=1.40, p=.241$, $\eta_{p}{ }^{2}=.003$, as the ecology $\mathrm{x}$ position interaction was statistically significant in the impression formation instruction condition, $F(3,603)=8.22, p<.001, \eta_{p}{ }^{2}=$ .04 , as well as in the memory task instruction condition, $F(3,609)=13.92, p<.001, \eta_{p}{ }^{2}=.06$. There was also no significant main effect of instruction condition, $F(1$, 404) $=0.34, p=.769, \eta_{p}{ }^{2}=.001$.

Figure 6 illustrates the ecology $x$ position interaction collapsed across both instruction conditions, which mirrors the pattern found in the previous experiments. Simple contrast analyses found that the interaction was again significant for all three comparisons when CS2, CS3, and CS4 were compared to CS1 $\left(2\right.$ vs 1: $F(1,406)=9.75, p=.002, \eta_{p}{ }^{2}=.02 ; 3$ vs $1: F(1,406)=28.53, p<.001, \eta_{p}{ }^{2}=.07 ; 4$ vs. $1: F(1$, 406) $\left.=46.19, p<.001, \eta_{p}{ }^{2}=.10\right)$. As Figure 6 illustrates, the interaction again followed a linear trend, 
$F(1,406)=49.17, p<.001, \eta_{p}^{2}=.11$, while the quadratic trends was non-significant, $F(1,406)=1.31$, $p=.254, \eta_{p}{ }^{2}=.003$. Hence, the stronger influence of distinct compared to redundant US pictures on brand evaluations was more pronounced for laterencountered brands.

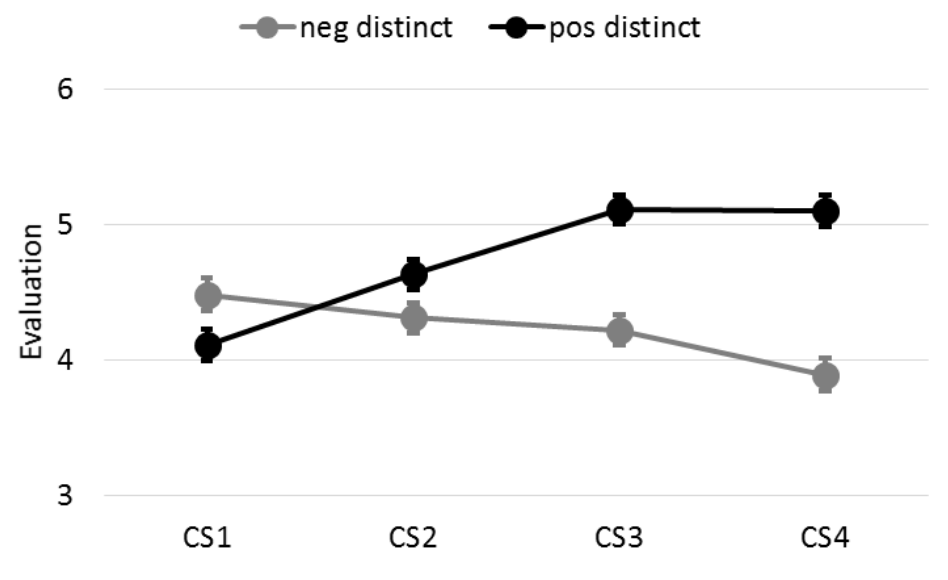

Figure 6. Evaluations of the four CS brands as a function of their serial learning position in the negative distinct and in the positive distinct ecologies, collapsed across both instruction conditions. Error bars represent standard errors of the means.

Learned Contingencies. We then tested whether participants had actually learned different CS-US pairing contingencies depending on the respective ecologies and serial learning positions. Participants had indicated for each of the 4 brands how often the brand was paired with a positive and how often it was paired with a negative picture. Based on these recalled pairing frequencies, we first calculated difference scores. That is, for each participant and for each brand, we subtracted the number of recalled negative pairings from the number of recalled positive pairings. Positive values indicate that participants overestimated the frequency of positive relative to negative pairings for the respective brand and vice versa. Twenty-three participants failed to provide all frequency estimates and had to be removed from the following analysis.

Similar to the analysis of the brand evaluations, we then specified a general linear model predicting the frequency differences from the factors ecology (between-subjects), instruction condition (between subjects), and position (within-subjects). As Figure 7's left part shows, the frequency differences mirror the brand evaluations. Accordingly, the analysis showed a significant main effect of ecology, $F(1,381)=25.79, p$ $<.001, \eta_{p}{ }^{2}=.06$, as in the positive distinct ecology, participants clearly overestimated the frequencies of positive relative to negative pairings $(M=0.44, S D=$ 0.79 ), while this was not the case in the negative distinct condition $(M=-0.01, S D=0.89)$.
In line with the differentiation principle, this main effect was qualified by an interaction with serial position $F(3,1143)=14.89, p<.001, \eta_{p}{ }^{2}=.04$. As illustrated in the left part of Figure 7, the main effect of ecology depended on the serial position of the brands, mirroring the pattern for the brand evaluations. That is, the effect of ecology was more pronounced for laterencountered brands than for earlier-encountered CS brands. Simple contrast analyses found that the interaction was significant for all three comparisons when CS2, CS3, and CS4 were compared to CS1 (2 vs $1: F(1,381)=8.27, p=.004, \eta_{p}{ }^{2}=.02 ; 3$ vs $1: F(1,381)$ $=24.98, p<.001, \eta_{p}{ }^{2}=.06 ; 4$ vs. $1: F(1,381)=30.43$, $\left.p<.001, \eta_{p}{ }^{2}=.07\right)$. As Figure 7 illustrates, the interaction clearly followed a linear trend, $F(1,381)=$ $32.68, p<.001, \eta_{p}{ }^{2}=.08$, while the quadratic trend was non-significant, $F(1,381)=1.21, p=.271, \eta_{p}{ }^{2}=.00$.

The different instruction conditions (impression formation vs. memory) had no significant influences on recalled frequencies. The instructions main effect was close to conventional significance levels, $F(1,381)=$ 3.43, $p=.065, \eta_{p}{ }^{2}=.01$, as participants in the impression formation condition evaluated the brands somewhat more positively $(M=0.30, S D=0.06)$ than participants in the memory condition $(M=0.13, S D=$ 0.06). Neither the instruction's interaction with ecology was statistically significant, $F(1,381)=0.46, p=.498$, $\eta_{p}{ }^{2}=.001$, nor its interaction with serial position, $F(1$, $381)=1.55, p=.200, \eta_{p}{ }^{2}=.004$. 

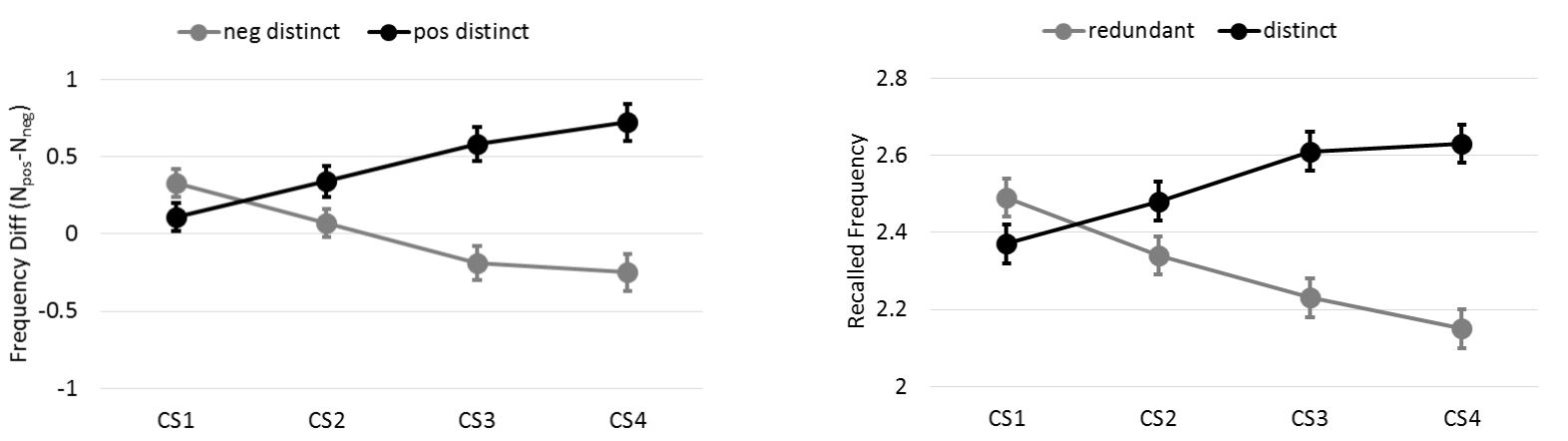

Figure 7. Left Panel: Difference scores of the recalled frequencies of positive and negative pairings for all four CS brands in the negative and in the positive distinct ecologies, collapsed across both instruction conditions. Right Panel: Recalled frequencies of distinct and redundant pairings for all four CS brands. Error bars represent the standard error of the mean.

Next, we tested whether the differential contingencies that participants had learned were due to a stronger impact of distinct pairings, or a weaker influence of redundant pairings, or both. We therefore analyzed the recalled frequencies of distinct and redundant pairings for the four brands, collapsed across both ecologies, and across both instruction conditions. We specified a general linear model predicting the recalled frequencies of distinct and redundant pairings (within-subjects) from their serial position (withinsubjects). As Figure 7's right part shows, the recalled frequencies of distinct pairings increased with serial position, while the recalled frequencies of redundant pairings decreased with serial position, which is expressed by a significant linear interaction between pairing type (distinct vs. redundant) and position, $F(1$, $384)=32.65, p<.001, \eta_{p}{ }^{2}=.08$. Hence, with increasing serial position of a brand, its distinct pairings seem to have an increasing impact during learning, while simultaneously, the impact of redundant pairings decreases.

Mediation Analysis. Next, we conducted mediation analysis using bootstrapping (Tingley, Yamamoto, Hirose, Keele, \& Imai, 2014) to test whether the present effects of ecology and serial position on brand evaluations could be explained by the differential learning of pairing contingencies. The potential mediator, learned contingencies, is expressed by the difference between number of recalled positive and negative pairings (see left part of Figure 7). We first fit a mixed-effects mediator model where the learned contingencies are modeled as a function of ecology, position, and their linear interaction, while subjects were treated as a random factor. Because instruction conditions had no significant influences on brand evaluations nor on the learned contingencies, this factor was not included in the mediation analysis. We then fit an outcome model that predicted the brand evaluations from the same factors, and the mediator (learned contingencies). Using the default number of quasi-Bayesian Monte Carlo simulations $(N=1000$; Tingely et al., 2014), we found that learned contingencies significantly mediated the effect of the ecology x position interaction on brand evaluations (b $=-0.04,95 \%$ confidence interval [CI; $-0.05,-0.03], p<$ .001 ), explaining about $31 \%$ of the total effect. This suggests that at least a substantial part of the differentiation principle in attitude formation may reflect actual differential learning of distinct and redundant co-occurrences.

\section{Discussion}

Experiment 5 provides several insights regarding the processes underlying the differentiation principle. First, differentiation occurred independent of the processing goal that was communicated to participants. When participants were instructed to merely remember the stimulus pairings, their brand evaluations followed the same pattern as under an impression formation instruction. While an impression formation goal may lead participants to infer that co-occurring US pictures are attributes of the brands, and thereby give rise to an attribute-based attitude formation process, we found that this processing goal was not a necessary condition for differentiation to occur.

Second, the present results suggest that the differentiation principle does not merely guide the weighing of information but that it guides actual learning. The pairing contingencies that participants had learned exactly resembled the pattern of the brand evaluations. With increasing serial position of a brand, participants more strongly overestimated the frequencies of distinct relative to redundant pairings. 
Mediation analysis further suggested that at least part of the differential brand evaluations was due to the learned contingencies. However, it should be noted that significant mediation constitutes a necessary but not a sufficient condition for inferring causality (Fiedler, Harris, \& Schott, 2018; Fiedler, Schott, \& Meiser, 2011).

In sum, Experiment 5 suggests that the differentiation principle at least partly manifests itself as a learning phenomenon. Yet, there remains an important caveat at this point. We asked participants to recall the pairing contingencies only after they had evaluated the brands. Possibly, the recalled contingencies were influenced by the previouslyexpressed brand evaluations, which is suggested by the high similarity of the patterns. For example, participants could have felt obliged to justify their differential brand evaluations. In the following Experiment 6, we switched the order and asked participants for the pairing contingencies before the brand evaluations.

\section{Experiment 6: Contingency Recall before} Evaluations

Experiment 6 aimed to rule out that the differentially learned pairing contingencies were influenced by the brand evaluations; hence, we assessed contingencies before evaluations. Because Experiment 5 found no effects of processing goal, Experiment 6 only realized the impression formation instruction parallel to Experiments 1 to 4 .

\section{Methods}

Participants and design. Experiment 6 omitted the between-participants factor instructions condition, and therefore, we again aimed for a sample size of 200 . We ended up collecting data from 201 students of a large university (126 female, 75 male), who participated for course credit or candy. The design of Experiment 6 was similar to the previous Experiment 5, except that all participants again received an impression formation instruction (cf. Exp. 1-4).

Procedure and Materials. The procedure was also similar to that of the previous experiment except that participants provided recalled pairing frequencies before they provided brand evaluations. At the end of the experiments, all participants were thanked, debriefed, and compensated.

\section{Results}

CS Brand Evaluation. We specified a general linear model including the factors ecology (betweensubjects), and position (within-subjects). This time, the analysis found no significant main effect of ecology, $F(1,199)=0.03, p=.856, \eta_{p}{ }^{2}=.0002$. However, in line with the differentiation principle, there was again an interaction between ecology and position $F(3,597)=$ $16.34, p<.001, \eta_{p}{ }^{2}=.08$. Figure 8 illustrates that brand evaluations in the negative distinct ecology became more negative with increasing serial position, while the reverse was found in the positive distinct ecology. Simple contrast analyses found that the interaction was again significant for all three comparisons when CS2, CS3, and CS4 were compared to CS1 $(2$ vs 1: $F(1,199)$ $=10.59, p=.001, \eta_{p}{ }^{2}=.05 ; 3$ vs $1: F(1,199)=25.11$, $p<.001, \eta_{p}{ }^{2}=.11 ; 4$ vs. $1: F(1,199)=37.93, p<.001$, $\left.\eta_{p}{ }^{2}=.16\right)$. As Figure 8 illustrates, the interaction again followed a linear trend, $F(1,199)=39.75, p<.001, \eta_{p}{ }^{2}$ $=.17$, while the quadratic trend was non-significant, $F(1,199)=1.11, p=.294, \eta_{p}^{2}=.01$.

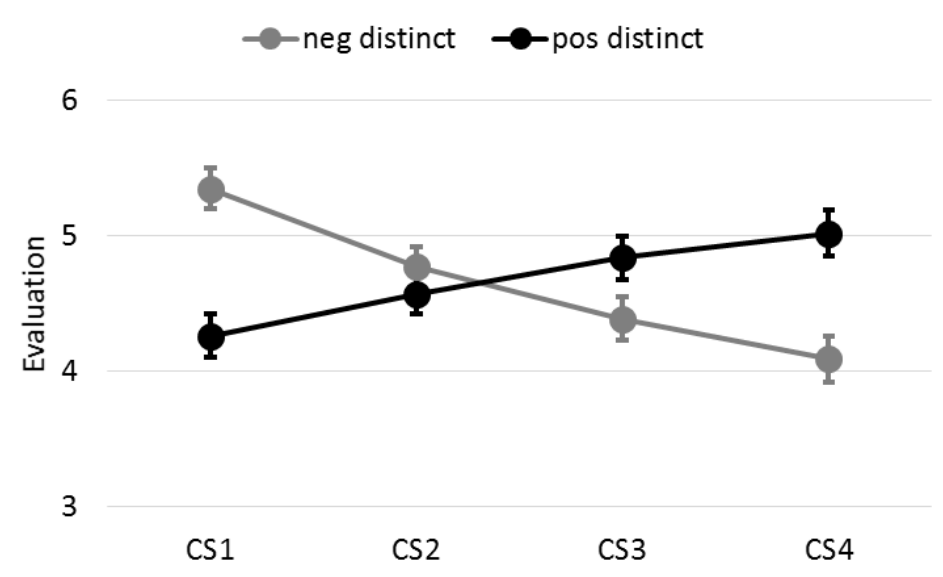

Figure 8. Evaluations of the four CS brands as a function of their serial learning position in the negative distinct and in the positive distinct ecologies. Error bars represent standard errors of the means. 
Learned Contingencies. For each participant and for each brand, we again subtracted the number of recalled negative pairings from the number of recalled positive pairings. Positive values indicate that participants overestimated the frequency of positive relative to negative pairings for the respective brand and vice versa. We specified a general linear model predicting the frequency differences from the factors ecology (between-subjects) and position (withinsubjects). As in the previous experiment, this analysis found a significant main effect of ecology, $F(1,199)=$ $17.55, p<.001, \eta_{p}{ }^{2}=.08$. In the positive distinct ecology, participants overestimated the frequencies of positive relative to negative pairings $(M=0.48, S D=$ 0.81 , while this was not the case in the negative distinct condition $(M=-0.06, S D=1.00)$.

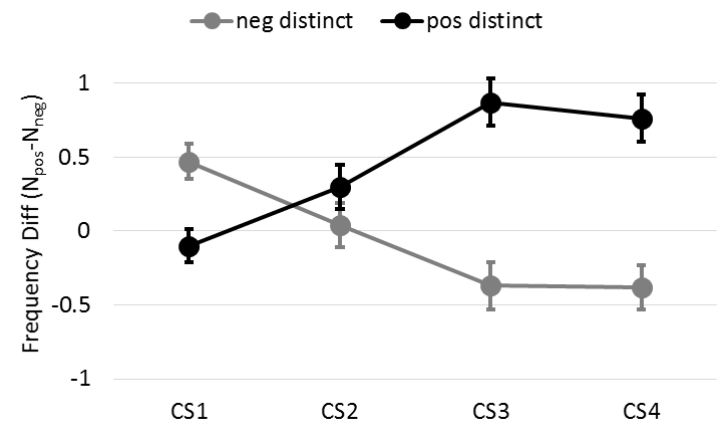

This main effect was again qualified by an interaction with serial position $F(3,597)=18.87, p<$ $.001, \eta_{p}{ }^{2}=.08$. As Figure 9's left part shows, the main effect of ecology depended on the serial position of the brands, resembling the pattern for the brand evaluations. That is, the effect of ecology was more pronounced for later-encountered brands than for earlier-encountered brands. Simple contrast analyses found that the interaction was significant for all three comparisons when CS2, CS3, and CS4 were compared to CS1 (2 vs 1: $F(1,199)=10.57, p=.001, \eta_{p}{ }^{2}=.05 ; 3$ vs $1: F(1,199)=43.46, p<.001, \eta_{p}{ }^{2}=.18 ; 4$ vs. $1: F(1$, $\left.199)=37.38, p<.001, \eta_{p}{ }^{2}=.16\right)$. As Figure 9 illustrates, the interaction clearly followed a linear trend, $F(1,199)=43.89, p<.001, \eta_{p}{ }^{2}=.18$, while a smaller quadratic trend was also significant, $F(1,199)$ $=6.48, p=.012, \eta_{p}{ }^{2}=.03$.

Figure 9. Left Panel: Difference scores of the recalled frequencies of positive and negative pairings for all four CS brands in the negative and in the positive distinct ecologies. Right Panel: Recalled frequencies of distinct and redundant pairings for all four CS brands. Error bars represent the standard error of the mean.

Next, we again analyzed the recalled frequencies of distinct and redundant pairings separately, collapsed across both ecologies. We specified a general linear model predicting the recalled frequencies of distinct and redundant pairings (within-subjects) from their serial position (within-subjects). As Figure 9's right part shows, recalled frequencies of distinct pairings increased with serial position, while recalled frequencies of redundant pairings decreased with serial position, which is expressed by a significant linear interaction between pairing type (distinct vs. redundant) and position, $F(1,200)=44.13, p<.001$, $\eta_{p}{ }^{2}=.18$. Hence, with increasing serial position of a brand, its distinct pairings had an increasing impact on the learned contingencies, and simultaneously, its redundant pairings have a decreasing impact on the learned contingencies.

Mediation Analysis. Parallel to Experiment 5, we conducted a mediation analysis using bootstrapping to test whether the present effects of ecology and serial position on brand evaluations could be explained by the differential learning of pairing contingencies. This analysis again found that learned contingencies significantly mediated the effect of the ecology $\mathrm{x}$ position interaction on brand evaluations $(b=-0.05$, 95\% confidence interval [CI; $-0.07,-0.03], p<.001$ ), explaining about $28 \%$ of the total effect.

\section{Discussion}

Experiment 6 again replicated the differentiation principle in Evaluative Conditioning as laterencountered brands were primarily evaluated based on their distinct co-occurrences. In a positive distinct ecology, later-encountered brands were evaluated more positively than earlier-encountered brands, and vice versa. For the first time, Experiment 6 found no significant main effect of ecology as the effect of 
ecology fully dependent on the serial position of the brands. It is likely that this change in the brand evaluation pattern was caused by participants recalling the pairing frequencies prior to brand evaluations. Hence, it seems that the recall of the pairing frequencies increased differential evaluations of the brands within participants.

Crucially, the brand evaluation pattern was again mirrored by the contingencies that participants had learned and were asked to reproduce. That is, participants overestimated the frequency of distinct relative to redundant pairings for later-encountered brands. More specifically, with increasing serial position of a brand, the impact of distinct pairings on the learned contingencies increased while simultaneously the impact of redundant pairings decreased.

Experiment 6 ruled out that participants based their frequency estimates on their previously provided brand evaluations, as may have been the case in Experiment 5. Instead, we found evidence for differential learning of contingencies when participants provided their frequency estimated before evaluating the brands. In addition, the learned contingencies mediated a substantial part of the differential brand evaluations. This again suggests that the differentiation principle at least partly operates at the learning stage, and does not result from differential weighing of otherwise accurately learned co-occurrences.

Yet, there remain two concerns regarding the interpretation that the differentiation principle manifests itself in differential learning. First, even though participants in Experiment 6 provided the pairing contingencies before evaluating the brands, they may nevertheless have formed positive or negative attitudes about the brands during learning, and these attitudes may then have guided their contingency estimates. To overcome this problem, the final Experiment 7 paired brands with distinct and redundant pictures of neutral objects instead of positive and negative pictures, and tested whether these produced the same differential learning of contingencies. If the contingency learning difference between distinct and redundant pairs is (as we hypothesize) not caused by the evaluative change, it should also occur after pairings with neutral pictures.

The omission of affectively charged US pictures also circumvents a second problem, namely that the differential learning of contingencies may still reflect some kind of affective fading of repeatedly presented stimuli. If repeated stimuli lose their affective potential, this may also diminish learning of their co-occurrences.
While Experiments 3 and 4 found that redundant compared to distinct US pictures were evaluated as more strongly positive and negative, it remains possible that affective fading was not picked up by the evaluative ratings.

\section{Experiment 7: Non-evaluative differentiation}

The final Experiment 7 tested whether the differentiation principle also guides contingency learning for non-evaluative stimuli. Specifically, we predicted that with increasing serial position of an attitude object (brand), distinct compared to redundant stimulus pairings have a stronger impact on the learned contingencies. In Experiment 7, we therefore replaced the affectively-charged US pictures with pictures of neutral objects from different categories (e.g., keys, tables, and mugs) and paired these with the brand pictures. Pictures from one object category were redundantly paired with all 4 brands, while pictures form another category were distinctly paired with each specific brand. After the learning phase, participants were asked to recall the pairing contingencies, similar as in Experiments 5 and 6. Participants also evaluated the CS brands as well as the US pictures to fully rule out that any kind of evaluative conditioning had taken place that might have caused differential learning of contingencies. We pre-registered Experiment 7 (http://aspredicted.org/blind.php? $\mathrm{x}=\mathrm{k} 6 \mathrm{kw} 7 \mathrm{k}$ ).

\section{Methods}

Participants and design. We again aimed for a sample size of 200, and ended up collecting data from 204 students of a large university (121 female, 83 male), who participated for course credit or candy. The design of Experiment 7 was similar to the previous Experiment 6, except that there was no ecology factor anymore as US pictures were neutral instead of positive or negative.

Procedure and Materials. The procedure was also similar to that of the previous experiment except that US brands co-occurred with pictures of neutral objects instead of IAPS pictures. The new US pictures were taken from a larger set of objects pictures (Konkle, Brady, Alvarez, \& Oliva, 2010), from which we selected 8 different exemplars from 8 different object categories (hairbrushes, helmets, keys, mugs, pods, suitcases, and tables). For each participant, the computer program randomly selected two categories and then selected 8 exemplar pictures from one category as the distinct US pictures, and two exemplar pictures from the other category as the redundant US 
pictures. During the learning stage, each brand was paired with a total of four US pictures, the two redundant pictures and two of the eight distinct pictures. Thus, two pictures from one object category were redundantly paired with all brands, while the eight pictures from the other category were distinctly paired with specific brands.

After the learning phase, participants were asked to recall the pairing contingencies. Specifically, they were asked to recall "how often each of the brands occurred together with a picture of a [name of redundant object category], and how often it occurred together with a picture of a [name of distinct object category". Participants were then sequentially presented with all four brands along with text boxes, and for each brand they were asked to provide the number of times this brand had occurred together with a picture form the redundant and from the distinct categories. The order of the brands was the same as in the learning phase. Participants were then again asked to evaluate the brands as well as the US pictures.

At the end of the experiment, all participants were thanked, debriefed, and compensated.

\section{Results}

Learned Contingencies. In line with our preregistered analysis plan, we first subtracted the number of recalled redundant pairings from the number of recalled distinct pairings. Positive values indicate that participants overestimated the frequency of distinct relative to redundant pairings for the respective brand and vice versa. We specified a general linear model predicting the frequency differences from the factor position (within-subjects).

This analysis found a significant intercept, $F(1,203)$ $=27.79, p<.001, \eta_{p}{ }^{2}=.12$, indicating that participants overestimated the frequency of distinct compared to redundant pairings. In line with the differentiation principle, the analysis also revealed a significant effect of position $F(1,203)=7.03, p<.001, \eta_{p}{ }^{2}=.03$.

As illustrated in Figure 10, participants' learned contingencies equally reflected redundant and distinct pairings for the first brand they encountered, while the learned contingencies for the later-encountered brands more strongly reflected distinct pairings.

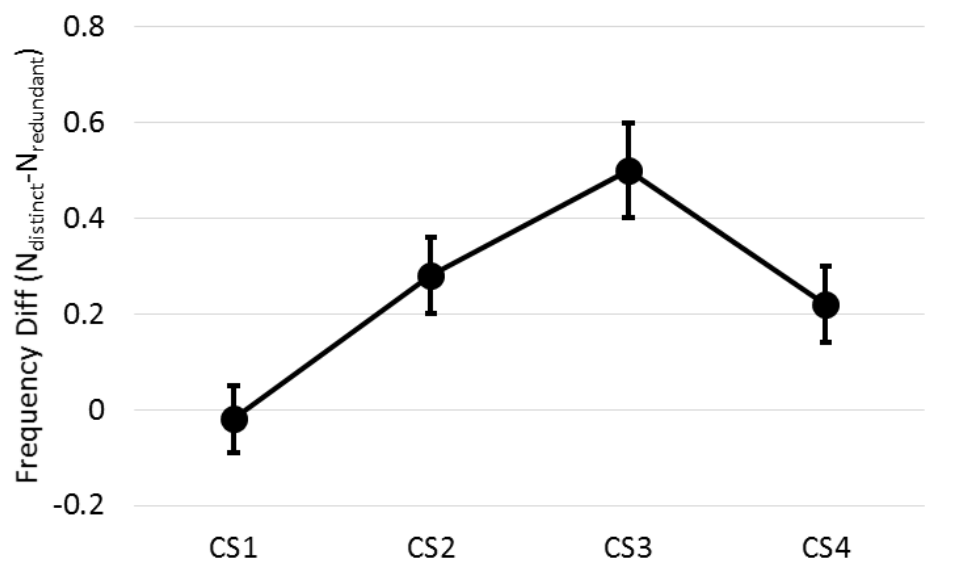

Figure 10. Difference scores of the recalled frequencies of distinct and redundant pairings for all four CS brands. Error bars represent standard errors of the means.

Simple contrast analyses found that the interaction was significant for all three comparisons when CS2, CS3, and CS4 were compared to CS1 (2 vs 1: $F(1,203)$ $=8.48, p=.004, \eta_{p}{ }^{2}=.04 ; 3$ vs $1: F(1,203)=17.28, p$ $<.001, \eta_{p}{ }^{2}=.08 ; 4$ vs. $1: F(1,203)=5.91, p=.016, \eta_{p}{ }^{2}$ $=.03)$. As shown in Figure 10, the effect of position followed a linear trend, $F(1,203)=7.55, p=.007, \eta_{p}{ }^{2}$ $=.04$, as well as a quadratic trend, $F(1,203)=12.28, p$ $=.001, \eta_{p}{ }^{2}=.06$.

CS and US Evaluation. Even though we selected US pictures from rather neutral object categories, we could not rule out that pictures from some object categories may be perceived as more positive or negative than pictures from other categories, which may then give rise to an Evaluative Conditioning effect. If this was the case, participants may base their pairing frequency judgments on their positive or negative impression of the brands, an alternative explanation for the present findings. In line with our pre-registered analysis plan, we therefore analyzed US picture and CS brand evaluations to test for a possible Evaluative Conditioning effect. 
For each participant, we first calculated the mean evaluations of US pictures from both object categories. For ten participants these means were exactly equal, meaning that these participants did not perceive any valence differences between the pictures from the two categories. These ten cases were then removed from the following analysis. For the remaining participants, it was determined which of the two categories was the more positive category, which was the more negative category, and which of these categories was redundantly paired with the brands and which was distinctly paired. This resulted in the creation of a posthoc ecology factor (positive distinct / negative redundant vs. negative distinct / positive redundant), similar to the previous experiments.

We then specified a general linear model that predicted CS brand evaluations from the factors ecology (between-subjects), and position (withinsubjects) to test whether an evaluative conditioning effect had occurred that was sensitive to the distinctiveness of the pairings and to the serial position of the brands. This analysis found no significant effects (all Fs $<1$ ), which means that the differentiation principle evident in the learned contingencies did most likely not originate from an Evaluative Conditioning effect, that is, from participants' affective or evaluative reactions to the US pictures.

\section{Discussion}

Experiment 7 shows that distinct and redundant stimulus co-occurrences have a differential impact on the contingencies that perceivers learn. That is, perceivers overestimate the frequency of distinct stimulus co-occurrences relative to redundant stimulus co-occurrences. Crucially, this effect also hinges on the serial position within the learning sequences, as the overestimation of distinct compared to redundant cooccurrences appeared and became stronger for laterencountered brands. These findings are yet another demonstration of the differentiation principle: When perceivers try to extract the regularities in their learning environment, they prioritize information that differentiates a novel attitude object from previously encountered ones (i.e., distinct co-occurrences).

Importantly, the present experiment confirms that at least part of the differentiation principle in attitude formation as evident in the present experiments, constitutes a true learning effect. That is, the present results render the two limitations that remained after the previous experiment rather unlikely. First, given that US pictures depicted neutral objects which did not lead to differential evaluations of the paired brands, it is unlikely that participants based their pairing frequency estimates on attitudes they had formed about the brands. Second, the usage of neutral CS pictures also renders it unlikely that the differential learning effect was due to affective fading of redundant US pictures. Instead, the present results suggest that distinct and redundant information have a differential impact on learning during the formation of attitudes. Specifically, information that differentiates an attitude object from previously-encountered ones enjoys priority during learning.

\section{General Discussion}

We started with the observation that attribute-based attitude formation follows a differentiation principle. When people form attitudes about persons, groups, or objects by learning about their attributes, the resulting attitudes primarily reflect distinct attributes that differentiate a given attitude object from previouslyencountered ones (Alves et al., 2018; De Bruin \& Keren, 2003; Hodges, 1997; Houston et al., 1989, 1991).

The present work shows that this principle also applies to attitudes that are not based on attitude objects' attributes, but on co-occurring stimuli (i.e., Evaluative Conditioning). While co-occurrence-based attitude formation is often regarded as a more basic form of attitude formation that is not sensitive to the contingencies among stimulus pairings, and therefore not subject to cue competition effects, the present work strongly suggests otherwise. Similar to cancellation effects in attribute-based attitude formation, we found that attitudes towards initially neutral brands (CSs) were more strongly influenced by positive and negative pictures (USs) that distinctly co-occurred with the brands compared with USs that redundantly cooccurred with multiple brands. Also in line with attribute-based cancellation effects, the stronger influence of distinct pairings was sensitive to the brands' serial learning position, as it was stronger for later-encountered brands.

Across seven experiments, we gained several insights into the differentiation principle and how it guides co-occurrence-based attitude formation. In Experiments 1 to 6 participants observed a serial presentation of four different brands (CSs), and these were distinctly paired with two positive US pictures and redundantly paired with two negative US pictures (i.e., positive distinct ecology), or vice versa (i.e., negative distinct ecology). Distinct and redundant cooccurrences had a similar impact on participants' attitudes towards the first brand, as these were 
evaluated similarly in both ecologies. In line with the differentiation principle, evaluations of subsequently encountered brands then primarily reflected the valence of the distinctly co-occurring US pictures. That is, in the positive distinct ecology, later-encountered brands were evaluated more positively than the first brand, while the reverse was true in the negative distinct ecology.

While participants in Experiment 1 evaluated each brand before encountering the subsequent brands, Experiments 2 to 6 asked participants to evaluate all four brands at the end of the whole learning sequence. Hence, participants in these experiments had the chance to learn that the redundantly paired positive or negative US pictures were redundant among all CS brands. Yet, even when participants had access to the whole learning sequence before evaluating the brands, the relative impact of distinct and redundant pairings was nevertheless sensitive to the learning order. The stronger impact of distinct pairings followed overall a clear linear trend and increased with the brand's serial learning position. This pattern is remarkable because there is no rational informational basis for the differential brand evaluations. Note that while each brand co-occurred with the same number of positive and negative pictures, brand evaluations were quite divergent depending on the serial positions of the brands. In that sense, the increasingly positive or negative evaluation of later-encountered brands constitutes a true evaluative bias.

A possible explanation for this finding is that participants habituate to the redundantly paired US pictures, which then perpetually lose their affective potential. Though we cannot rule out affective fading as contributing factor entirely, Experiments 3 and 4 found that participants evaluated the redundantly paired pictures as more and not less evaluatively extreme than the distinctly paired pictures, which is in line with recent research showing that repetition increases subjective affective extremity of stimuli (Mrkva \& van Boven, 2020). The distinctly paired US pictures had thus a stronger influence on the brand evaluations than the redundantly paired pictures although they were perceived as less evaluatively extreme. A potential caveat to this is that the explicit US picture evaluations may not have picked up potential affective fading effect that may have occurred at an implicit level. Consider, however, that all the evaluative effects reported here are due to pairings with US pictures that were selected based on explicit evaluative ratings. This makes it in our opinion unlikely that an undetected evaluative fading occurred that is opposite to the indicated US picture ratings and strong enough to explain the present differentiation effects on the explicit brand evaluations. Yet, we cannot fully rule out a possible contribution of affective fading that operates at an implicit level.

Experiment 4 also randomly varied the order in which participants evaluated the brands at the end of the learning sequence and confirmed that differentiation was indeed a function of the learning order and not a function of the judgment order. While the stronger influence of distinct pairings increased with the brands' serial positions during the learning phase, serial position during the judgment phase had no systematic influence. This suggests that that differentiation guides attitude formation at the learning stage and not at the judgment stage.

Experiment 5 introduced participants' processing goals as a possible boundary condition of differentiation. Experiments 1 to 4 used an "impression formation" instruction, and previous research suggests that this may lead participants to draw inferences regarding the relation between CS brands and US pictures (Moran et al, 2015). Specifically, participants may have inferred that the US pictures constitute brand attributes, which may give rise to an attribute-based attitude formation process. Under a "memorization" processing goal, on the other hand, participants may be more sensitized to mere associative relations between CS and US (Moran et al, 2015). Experiment 5 therefore manipulated participants' processing goals via instructions; yet, it found that a "memorization" processing goal and an "impression formation" processing goal produced the same differentiation pattern.

Experiment 5 also addressed the question whether differentiation guides the learning or the weighting of distinct and redundant pairings. Specifically, distinct pairings may either have a processing advantage during the learning stage, alternatively, participants may learn all pairings equally, but then denote differential weight to distinct and redundant pairings when forming a summary evaluation. Experiment 5 therefore assessed the pairing contingencies that participants had learned by asking them to recall the positive and negative cooccurrence frequencies for each brand. Resembling the brand evaluation pattern, participants overestimated the frequency of distinct relative to redundant pairings, and this effect also increased with the brands' serial learning positions. Experiment 6 found the same pattern when participants provided pairing contingencies before evaluating the brands, thereby ruling out that brand evaluations influenced recalled 
contingencies. Mediation analyses in Experiments 5 and 6 confirmed that at least part of the differential impact of distinct and redundant co-occurrences on CS brand evaluations resulted from differential learning and not from differential weighting. Hence, it seems that those co-occurrences that differentiate an attitude object from previously-encountered ones enjoy priority during learning.

This conclusion was further supported by results from Experiment 7 that paired CS brands with pictures of neutral objects, thereby omitting any possible influence of US pictures' affective potential on the learned pairing contingencies. Again, participants overestimated the frequency of distinct relative to redundant pairings and this was again pronounced for later-encountered brands.

Across the seven experiments, the relative stronger impact of distinct compared to redundant pairings on brand evaluations and on learned pairing frequencies was mostly a linear function of serial brand position. This means that the more redundant a US picture became, the weaker was its impact relative to distinct pairings. This suggests that the psychological processes underlying the differentiation principle are in fact sensitive to different degrees of redundancy. However, some experiments also showed weaker support for a quadratic relation between serial brand position and the relatively stronger impact of distinct pairings. For the brand evaluations, this was the case in Experiment 1, where participants provided step-by-step brand evaluations. While we can only speculate why step-bystep evaluations gave rise to a quadratic effect and endof-sequence ratings produced linear effects, a possible reason is that step-by-step evaluations are less demanding for participants' memory. Relatedly, the quadratic effect may simply indicate that different degrees of redundancy eventually hit a ceiling when memory demand is low. In addition, Experiments 5 to 7 found some evidence for a quadratic relation between serial brand position and distinct pairings' stronger impact on learned contingencies. Most likely, these indicated the existence of a recency effect which gave rise to a somewhat more accurate recall of pairing frequencies for the most recently encountered brand.

Taken together, the present findings are the first to show that co-occurrence-based attitude formation follows a differentiation principle. Accordingly, what is learned about a given attitude object depends on what has previously been learned about other attitude objects. Any novel attitude object is likely to be evaluated based on information that differentiates it from already-known attitude objects. This shows that attitude formation, even when based on mere stimulus co-occurrences is essentially relative. The present findings have several further important theoretical and practical implications, which we will discuss in the following.

\section{Cognitive Processes Underlying Differentiation}

As discussed earlier, differentiation is a well-known guiding principle in attribute-based attitude formation where it manifests itself in so-called cancellation effects (Alves et al., 2018; De Bruin \& Keren, 2003; Hodges, 1997; Houston et al., 1989, 1991). The fact that we found similar effects in the domain of cooccurrence-based attitude formation suggests that these effects may all share common underlying processes. Cancellation effects are often assumed to result from a rather deliberate higher-order comparison process that involves differential weighing of distinct and redundant attributes. In contrast, the present results suggest that distinct compared to redundant information may actually have a processing advantage during learning as evident from the differential pairing contingencies that participants recalled.

Whether this differential learning also applies to attribute learning, that is, whether distinct attributes have a similar processing advantage as distinct stimulus pairings needs to be tested by future research. If confirmed, a plausible cognitive process underlying the differentiation principle may be attention. Note that distinct pairings as well as attributes are more surprising to the perceiver than redundant ones. In theories about Classical Conditioning (Rescorla \& Wagner, 1972), and human contingency learning (Kruschke, 2003; Sherman et al., 2009), surprise is indeed considered the major driver of learning. These theories assume that learning is based on predictoroutcome relations, or signaling processes, that are sensitive to stimulus contingencies. Accordingly, surprising, or unpredicted learning instances have a learning advantage, because they are more likely to reflect a causal relationship between a predictor and an outcome.

Kruschke (2001; 2003) formalized these considerations in a theory of attentional leaning, which argues that during cue learning, people flexibly shift their attention from irrelevant to relevant cues, and that learning for an ignored cue is inhibited (see also Kruschke \& Blair, 2000; Mackintosh, 1975). This attention shift gives priority to surprising learning instances and provides a unifying explanation for typical cue competition effects such as blocking (Kamin, 1968), and overshadowing (Pavlov, 1927; 
Mackintosh, 1976). Applying the idea of attention shift to attitude formation, a distinct pairing, or attribute, may enjoy attentional priority resulting in enhanced learning and a stronger influence on resulting attitudes.

\section{Cue Competition in Evaluative Conditioning}

Regardless of the specific process underlying the present effects, they do challenge the assertion that cooccurrence-based attitude formation (Evaluative Conditioning) constitutes a form of learning that is sensitive only to the spatiotemporal contiguity between stimuli, but not to their contingencies (Baeyens et al., 1996; Baeyens, Hendrickx, Crombez, \& Hermans, 1998; De Houwer et al., 2001). The independence of contingencies has often been argued to show that Evaluative Conditioning is distinct from other forms of learning such as Classical Conditioning or attribute learning (De Houwer et al., 2001; but see Davey, 1994). For example, in contrast to Classical Conditioning, Evaluative Conditioning was not found to be subject to cue competition that alters pairing contingencies, as described by the phenomena of blocking (Kamin, 1968), and overshadowing (Pavlov, 1927; Mackintosh, 1976).

However, as anticipated in the introduction, the empirical evidence for an absence of cue competition effects in Evaluative Conditioning is rather limited (Beckers et al., 2009; Dwyer et al., 2007). In light of this limited evidence, the suggestion by De Houwer and colleagues (2001, p. 866) may still hold that "it is likely that data on cue competition in EC will have a major impact on theories of EC". If one was to interpret the present results as evidence for cue competition, one may conclude that Evaluative Conditioning is sensitive to cue competition after all. Accordingly, in the present paradigm, multiple CS (brands) competed for an association with the same redundant US (picture), and this competition weakened the associations between each CS brand and the US picture.

One reason why previous studies found no cuecompetition effects in Evaluative Conditioning may be the nature of the standard paradigm, which these studies used (Beckers et al., 2009; Dwyer et al, 2007). In that paradigm, each participant observes attitude objects that are paired only with positive USs and other attitude objects that are paired only with negative USs. The Evaluative Conditioning effect is then quantified as the difference between evaluations of positively paired and negatively paired attitude objects. In the present work's paradigm, on the other hand, attitude objects are all ambivalently paired, as they co-occur with positive and negative US pictures. Due to this ambivalence and the resulting evaluative similarity among the attitude objects, the present set-up may ensure high sensitivity to factors that modulate Evaluative Conditioning including cue competition. In the standard paradigm, on the other hand, the learning ecology is dominated by the clear contrast between positively paired and negatively paired attitude objects, which may render modulating factors undetectable.

\section{Implications for Theories of Evaluative Conditioning}

How do the present findings fit with existing theories about Evaluative Conditioning? Our findings most clearly violate the referential learning idea according to which EC effects are due to association formations that are only sensitive to CS-US contiguities but not to their contingencies (Baeyens et al., 1993; 1996; 1998). Hence, if EC does reflect referential, or associative learning, this account must add an assumption that associations are stronger between distinctly compared to redundantly paired stimuli.

Another prominent theory argues that Evaluative Conditioning reflects an implicit misattribution of the affect that is induced by the positive or negative US onto the attitude object (CS) (Jones et al., 2009). According to this idea, EC effects are also insensitive to CS-US contingencies, as each co-occurrence provides an opportunity for valence transfer (Jones et al., 2010). Yet, the implicit misattribution account may predict the present results, assuming that redundantly paired US pictures lose their affective potential. While US picture evaluations from Experiments 3 and 4 suggested the opposite, it remains possible that affective fading cannot be captured by explicit evaluations. In addition, even though Experiment 7 showed that contingency learning is guided by differentiation even when stimuli are not affectively charged, we cannot rule out that part of the differential brand evaluations that we found in Exp. 1 to 6 are due to some form of affective fading. More research is needed to test for a potential fading of implicit affective reactions towards redundant pairings, and if confirmed, this would further validate the implicit misattribution account as a whole.

A third group of theories argues that Evaluative Conditioning reflects propositional inferences that perceivers draw about the relation between the CS and the US (De Houwer, 2007; De Houwer, 2018; De Houwer \& Hughes, 2016; Fiedler \& Unkelbach, 2016; Gast \& De Houwer, 2012). From this perspective, cooccurrence based attitude formation is not so different from attribute-based attitude formation because 
perceivers may draw the propositional inference that the co-occurring stimuli are somehow related. This perspective relates Evaluative Conditioning to impression formation and persuasion research. Information about the stimulus relation can be based on different sources, such as instructions, observations, interventions, and inferences. The observation of redundant versus distinct stimulus pairings can certainly be argued to be information that is relevant for the interpretation of the stimulus relation. Whether and how exactly, perceivers draw the inference that distinct pairings are particularly important, however, has not been specified by propositional models. Based on our results, one can argue that not the relevance weighting of pairings, but differential learning is the driving mechanism. From the perspective of propositional models one might thus argue that because distinct pairings are more likely to be learned, it is also more likely that propositions about distinct stimulus relations are formed. However, to our knowledge, such a prediction has not yet derived from propositional models.

A fourth, more recent group of theories argues that Evaluative Conditioning is based on explicit or episodic memory for stimulus pairings (Aust, Haaf, \& Stahl, 2019; Gast, 2018; Stahl \& Aust, 2018). Although these models have not explicitly predicted the present differentiation effects in the past, they are in line with the findings from Experiments 5 to 7, which showed that part of the differentiation effect was explained by differential memory for the pairing contingencies.

\section{Practical Implications}

Stimulus co-occurrences can be observed in our daily lives anywhere at any time and we can expect that these will affect the attitudes that we form towards any kind of attitude object. For example, products, brands, individuals, or groups may co-occur with positive stimuli such as beautiful environments, exiting events, or pleasant smells, but they may also co-occur with negative stimuli such as fear-inducing environments, negative news headlines, or stigmatized social groups. As argued earlier, some these co-occurrences are more likely to be distinct, others are likely to be redundant. The present findings imply that people's attitudes will be most strongly influenced by stimuli that distinctly co-occur with an attitude object, and less by redundant co-occurrences.

A domain in which stimulus co-occurrence is of particular importance for attitude formation is advertising (e.g., Walther \& Grigoriadis, 2004; Sweldens et al., 2010). Brands and products are often presented together with a positive stimulus like a beautiful landscape, happy music, or a popular celebrity. The brand or product thereby assimilates to the other stimuli's positivity. The present work suggests that successful advertisement campaigns need to establish positive distinctiveness. Positive stimuli that accompany a brand or a product are more effective in creating a positive attitude when they distinctly cooccur with the brand or product. While typical positive context stimuli like beautiful landscapes or happy actors redundantly co-occur with all kinds of brands and products, celebrities on the other hand, constitute more distinct positive stimuli that may therefore be more effective in establishing positive brand attitudes. However, even among celebrities, there may be differences regarding their distinctiveness. A celebrity like Christiano Ronaldo for example, redundantly appears in the context of many different brands, while the "most interesting man in the world", Jonathan Goldsmith serves as a rather distinct positive stimulus for the beer brand Dos Equis.

The need for positive distinctiveness also applies to the social domain, where individuals may want to create a positive impression, for instance, in the context of a job application, or in a dating context. The present findings suggest that it pays off to create distinctiveness, for example, when crafting the design of a job application. Likewise, when setting up an online dating profile, one may provide favorable pictures of the self in unusual environments. The present research thereby confirms the intuition of human resources officers, hiring committees, and dating coaches - successful candidates need to establish distinctiveness.

Past research has also used Evaluative Conditioning as a tool to change some of people's attitudes that are considered problematic (for a recent meta-analysis, see Forscher et al., 2019). For example, co-occurrencebased procedures have been used to reduce negative attitudes towards social groups (French et al., 2013; Olson \& Fazio, 2006; Wennekers, Holland, Wigboldus, \& Van Knippenberg, 2012), or towards desirable behaviors like recycling (Geng, Liu, Xu, Zhou, \& Fang, 2013), and to increase negative attitudes towards problematic behaviors like smoking, snacking (Lebens et al., 2011; Schlenkermann, 2007), or towards maladaptive comparison standards like slim models (Martijn et al., 2013). The present work suggests that such interventions to change people's attitudes by exposing them to stimulus co-occurrences are most effective when attitude objects are paired with positive or negative stimuli that are distinct. 
Besides the general importance of distinctiveness for attitude formation, the present work also suggests that it is particularly important for attitude objects that are novel to perceivers. That is, novel products, brands, individuals, or groups will likely be evaluated based on those co-occurring stimuli that differentiate them from already-known ones. Hence, creating positive distinctiveness is especially important if you are introducing a novel product to the market, if you are the last one to be interviewed for a job, or if your dating partner has already been on a lot of dates before. Unfortunately, creating distinctiveness that is also positive is quite difficult in real life, a phenomenon, which we will discuss in the following.

\section{Distinct is usually negative}

The laboratory allows a systematic manipulation of the information ecology. Specifically, in the present experiment, we varied the distinctiveness and redundancy among positive and negative stimuli. However, in the real world, the information ecology is typically characterized by distinct negativity and redundant positivity (Alves, Koch, \& Unkelbach, 2017a, 2017b; Unkelbach, 2012). That is, negative information is more likely to vary across different objects, people, groups, or contexts, and is therefore distinct. Positive information on the other hand, is likely to be consistent across different objects, people, groups, or contexts, and is therefore rather redundant. This follows from the higher frequency of positive information (Alves et al., 2017a, Fiske, 1980, Hamilton \& Gifford, 1976, Sears, 1983; Wood \& Furr, 2016), as well from the larger diversity of negative information (Alves, Koch, Unkelbach, 2016, 2017b; Koch, Alves, Krüger, \& Unkelbach, 2016; Leising, Ostrovski, Zimmermann, 2013), two asymmetries that characterize the information ecology (see Unkelbach et al., 2019).

Consequently, distinct stimulus co-occurrences that differentiate different objects, individuals, or groups are likely to be negative. Creating positive distinctiveness is therefore quite challenging. According to the differentiation principle, this should be especially problematic for "novel" attitude objects. These will be most strongly evaluated based on their distinct attributes and co-occurring stimuli, and hence, they suffer an evaluative disadvantage compared to established attitude objects. Hence, the differentiation principle may contribute to a number of well-known evaluative biases, including people's preference for the status-quo over change (Fernandez \& Rodrik, 1991; Kim \& Kankanhalli, 1991; Samuelson \& Zeckhauser,
1988), their preference for pioneering brands over novel brands (Brown \& Lattin, 1994; Kardes \& Kalyanaram, 1992), as well as their preference for familiar social groups and individuals over novel groups and individuals (Alves et al., 2018; Hewstone, Rubin, \& Willis, 2002).

\section{Attribute-based and Co-occurrence-based Attitude Formation}

The present work not only demonstrates commonalities among different forms of cooccurrence-based learning (i.e., Evaluative Conditioning, Classical Conditioning, and human contingency learning), but more broadly, it demonstrated commonalities among co-occurrencebased and attribute-based attitude formation. These two types of attitude formation are located within related but quite distinct research traditions. Attributes are the main means of attitude formation in persuasion, impression formation, and choice formation, and cooccurrences are the main means in Evaluative Conditioning, Classical Conditioning, and human contingency learning.

The present work strongly suggests that the same differentiation principle that guides attribute-based attitude formation also applies to co-occurrence-based attitude formation.

The broader implication of such a common differentiation principle in attitude formation is that attribute-based and co-occurrence-based attitude formation may be not that different after all (De Houwer, \& Hughes, 2016).

\section{Conclusion}

When people form attitudes based on explicit examination of an attitude object's attributes, they primarily rely on distinct attributes that differentiate the object from previously-encountered ones. The present work found that this differentiation principle also applies to attitudes that result from the observation of mere stimulus co-occurrences. Specifically, cooccurrence-based attitudes are primarily influenced by positive and negative stimuli that distinctly co-occur with an attitude object and that differentiate it from previously-encountered ones. This shows that even in its most basic form, attitude formation is essentially relative. 


\section{References}

Agostinelli, G., Sherman, S. J., Fazio, R. H., \& Hearst, E. S. (1986). Detecting and identifying change: additions versus deletions. Journal of Experimental Psychology: Human Perception and Performance, 12, 445.

Allen, C. T., \& Madden, T. J. (1985). A closer look at classical conditioning. Journal of Consumer Research, 12, 301-315.

Allport, G. W. (1935). Attitudes. In C. M. Murchison (Ed.), Hand book of Social Psychology. Winchester, MA: Clark University Press.

Alves, H. (2018). Sharing rare attitudes attracts. Personality and Social Psychology Bulletin, 44, 1270-1283.

Alves, H., Koch, A., \& Unkelbach, C. (2016). My friends are all alike - the relation between liking and perceived similarity in person perception. Journal of Experimental Social Psychology, 62, 103-117.

Alves, H., Koch, A., \& Unkelbach, C. (2017). The "common good" phenomenon: Why similarities are positive and differences are negative. Journal of Experimental Psychology: General, 146, 512.

Alves, H., Koch, A., \& Unkelbach, C. (2017). Why good is more alike than bad: Processing implications. Trends in Cognitive Sciences, 21, 69-79.

Alves, H., Koch, A., \& Unkelbach, C. (2018). A CognitiveEcological Explanation of Intergroup Biases. Psychological Science, 29, 1126-1133.

Anderson, N. H. (1965). Averaging versus adding as a stimuluscombination rule in impression formation. Journal of Experimental Psychology, 70, 394.

Anderson, N. H. (1971). Integration theory and attitude change. Psychological Review, 78, 171.

Asch, S. E. (1946). Forming impressions of personality. The Journal of Abnormal and Social Psychology, 41, 258.

Aust, F., Haaf, J. M., \& Stahl, C. (2019). A memory-based judgment account of expectancy-liking dissociations in evaluative conditioning. Journal of Experimental Psychology: Learning, Memory, and Cognition, 45, 417-439.

Baeyens, F., Crombez, G., De Houwer, J., \& Eelen, P. (1996). No evidence for modulation of evaluative flavor-flavor associations in humans. Learning and Motivation, 27, 200-241.

Baeyens, F., Crombez, G., Van den Bergh, O., \& Eelen, P. (1988). Once in contact always in contact: Evaluative conditioning is resistant to extinction. Advances in Behaviour Re-search \& Therapy, 10, 179-199.

Baeyens, F., Eelen, P., \& van den Bergh, O. (1990). Contingency awareness in evaluative conditioning: A case for unaware affective-evaluative learning. Cognition and Emotion, 4, 3-18.

Baeyens, F., Eelen, P., Crombez, G., \& Van den Bergh, O. (1992). Human evaluative conditioning: Acquisition trials, presentation schedule, evaluative style and contingency awareness. Behaviour Research and Therapy, 30, 133-142.

Baeyens, F., Hendrickx, H., Crombez, G., \& Hermans, D. (1998). Neither extended sequential nor simultaneous feature positive training result in modulation of evaluative flavor-flavor conditioning in humans. Appetite, 31, 185-204.

Baeyens, F., Hermans, D., \& Eelen, P. (1993). The role of CS-US contingency in human evaluative conditioning. Behaviour Research and Therapy, 31, 731-737.
Baeyens F, Vansteenwegen D, Hermans D, Eelen P. Chilled white wine, when all of a sudden the doorbell rings: Mere reference and evaluation versus expectancy and preparation in human Pavlovian learning. In: Columbus F, editor. Advances in Psychology Research. Vol. 4. New York: Nova; 2001. pp. 241277.

Beckers, T., De Vicq, P., \& Baeyens, F. (2009). Evaluative conditioning is insensitive to blocking. Psychologica Belgica, 49, 41.

Brewer, M. B. (1968). Averaging versus summation in composite ratings of complex social stimuli. Journal of Personality and Social Psychology, 8, 20.

Bruner, J. S., \& Perlmutter, H. V. (1957). Compatriot and foreigner: A study of impression formation in three countries. The Journal of Abnormal and Social Psychology, 55, 253.

Brown, C. L., \& Lattin, J. M. (1994). Investigating the relationship between time in market and pioneering advantage. Management science, 40(10), 1361-1369.

Cohen, J. (1992). A power primer. Psychological Bulletin, 112, 155.

Conrey, F. R., \& Smith, E. R. (2007). Attitude representation: Attitudes as patterns in a distributed, connectionist representational system. Social Cognition, 25, 718-735.

Corneille, O., \& Stahl, C. (2019). Associative attitude learning: A closer look at evidence and how it relates to attitude models. Personality and Social Psychology Review, 23, 161189.

Davey G. C. L. (1994). Is evaluative conditioning a qualitatively distinct form of classical conditioning? Behaviour Research and Therapy, 32, 291-299.

De Bruin, W. B., \& Keren, G. (2003). Order effects in sequentially judged options due to the direction of comparison. Organizational Behavior and Human Decision Processes, 92, 91-101.

De Houwer, J. (2007). A conceptual and theoretical analysis of evaluative conditioning. The Spanish Journal of Psychology, 10, 230-241.

De Houwer, J. (2009). The propositional approach to associative learning as an alternative for association formation models. Learning \& Behavior, 37, 1-20.

De Houwer, J. (2018). Propositional models of Evaluative Conditioning. Social Psychological Bulletin, 13, e28046.

De Houwer, J. D., \& Beckers, T. (2002). A review of recent developments in research and theories on human contingency learning. The Quarterly Journal of Experimental Psychology: Section B, 55, 289-310.

De Houwer, J., \& Hughes, S. (2016). Evaluative conditioning as a symbolic phenomenon: On the relation between evaluative conditioning, evaluative conditioning via instructions, and persuasion. Social Cognition, 34, 480-494.

De Houwer, J., Thomas, S., \& Baeyens, F. (2001). Association learning of likes and dislikes: A review of 25 years of research on human evaluative conditioning. Psychological Bulletin, 127, 853.

Dwyer, D. M., Jarratt, F., \& Dick, K. (2007). Evaluative conditioning with foods as CSs and body shapes as USs: No evidence for sex differences, extinction, or overshadowing. Cognition and Emotion, 21, 281-299.

Fazio, R. H. (1989). On the power and functionality of attitudes: The role of attitude accessibility. In A. R. Pratkanis, S. J. Breckler, \& A. G. Greenwald (Eds.), Attitude structure and function (pp. 153-179). Hillsdale, NJ: Erlbaum. 
Fernandez, R., \& Rodrik, D. (1991). Resistance to reform: Status quo bias in the presence of individual-specific uncertainty. The American Economic Review, 1146-1155.

Fiedler, K., Harris, C., \& Schott, M. (2018). Unwarranted inferences from statistical mediation tests-An analysis of articles published in 2015. Journal of Experimental Social Psychology, 75, 95-102.

Fiedler, K., Schott, M., \& Meiser, T. (2011). What mediation analysis can (not) do. Journal of Experimental Social Psychology, 47, 1231-1236.

Fiedler, K., \& Unkelbach, C. (2011). Evaluative conditioning depends on higher order encoding processes. Cognition and Emotion, 25, 639-656.

Fishbein, M., \& Ajzen, I. (1974). Attitudes towards objects as predictors of single and multiple behavioral criteria. Psychological Review, 81, 59.

Fiske, S. T. (1980). Attention and weight in person perception: The impact of negative and extreme behavior. Journal of Personality and Social Psychology, 38, 889.

Förderer, S., \& Unkelbach, C. (2011). Beyond evaluative conditioning! Evidence for transfer of non-evaluative attributes. Social Psychological and Personality Science, 2, 479486.

Forscher, P. S., Lai, C. K., Axt, J. R., Ebersole, C. R., Herman, M., Devine, P. G., \& Nosek, B. A. (2019). A meta-analysis of procedures to change implicit measures. Journal of Personality and Social Psychology, 117, 522.

Fredrickson, B. L., \& Kahneman, D. (1993). Duration neglect in retrospective evaluations of affective episodes. Journal of Personality and Social Psychology, 65, 45.

French, A. R., Franz, T. M., Phelan, L. L., \& Blaine, B. E. (2013). Reducing Muslim/Arab stereotypes through evaluative conditioning. The Journal of Social Psychology, 153, 6-9.

Gast, A. (2018). A declarative memory model of evaluative conditioning. Social Psychological Bulletin, 13, e28590.

Gast, A., De Houwer, J., \& De Schryver, M. (2012). Evaluative conditioning can be modulated by memory of the CS-US pairings at the time of testing. Learning and Motivation, 43, 116126.

Gast, A., Gawronski, B., \& De Houwer, J. (2012). Evaluative conditioning: Recent developments and future directions. Learning and Motivation, 43, 79-88.

Gast, A., Langer, S. \& Sengewald, M.-A. (2016). Evaluative conditioning increases with temporal contiguity. The influence of stimulus order and stimulus interval on evaluative conditioning. Acta Psychologica, 170, 177-185.

Geng, L., Liu, L., Xu, J., Zhou, K., \& Fang, Y. (2013). Can evaluative conditioning change implicit attitudes towards recycling?. Social Behavior and Personality: an International Journal, 41, 947-955.

Gibson, B. (2008). Can evaluative conditioning change attitudes toward mature brands? New evidence from the Implicit Association Test. Journal of Consumer Research, 35, 178-188.

Hamilton, D. L., \& Gifford, R. K. (1976). Illusory correlation in interpersonal perception: A cognitive basis of stereotypic judgments. Journal of Experimental Social Psychology, 12, 392407.

Hammerl, M., Bloch, M., \& Silverthorne, C. P. (1997). Effects of US-alone presentations on human evaluative conditioning. Learning and Motivation, 28, 491-509.

Heinrich, J., Heine, S. J., \& Norenzayan, A. (2010). The weirdest people in the world. Behavioral and Brain Sciences, 33, 61-83.

Hewstone, M., Rubin, M., \& Willis, H. (2002). Intergroup bias. Annual Review of Psychology, 53, 575-604.
Hodges, S. D. (1997). When matching up features messes up decisions: The role of feature matching in successive choices. Journal of Personality and Social Psychology, 72, 1310 .

Hodges, S. D. (2005). A feature-based model of self-other comparisons. The self in social judgment, 131-153.

Hofmann, W., De Houwer, J., Perugini, M., Baeyens, F., \& Crombez, G. (2010). Evaluative conditioning in humans: a metaanalysis. Psychological Bulletin, 136, 390.

Hogarth, R. M., \& Einhorn, H. J. (1992). Order effects in belief updating: The belief-adjustment model. Cognitive Psychology, 24, 1-55.

Houben, K., Schoenmakers, T. M., \& Wiers, R. W. (2010). I didn't feel like drinking but I don't know why: The effects of evaluative conditioning on alcohol-related attitudes, craving and behavior. Addictive Behaviors, 35, 1161-1163.

Houston, D. A., Sherman, S. J., \& Baker, S. M. (1989). The influence of unique features and direction of comparison of preferences. Journal of Experimental Social Psychology, 25, 121-141.

Houston, D. A., Sherman, S. J., \& Baker, S. M. (1991). Feature matching, unique features, and the dynamics of the choice process: Predecision conflict and postdecision satisfaction. Journal of Experimental Social Psychology, 27, 411-430.

Houston, D. A., \& Sherman, S. J. (1995). Cancellation and focus: The role of shared and unique features in the choice process. Journal of Experimental Social Psychology, 31, 357378.

Hughes, S., Ye, Y., Van Dessel, P., \& De Houwer, J. (2019). When people co-occur with good or bad events: Graded effects of relational qualifiers on evaluative conditioning. Personality and Social Psychology Bulletin, 45, 196-208.

Hütter, M., \& Sweldens, S. (2013). Implicit misattribution of evaluative responses: Contingency-unaware evaluative conditioning requires simultaneous stimulus presentations. Journal of Experimental Psychology: General, 142, 638

Jones, C. R., Fazio, R. H., \& Olson, M. A. (2009). Implicit misattribution as a mechanism underlying evaluative conditioning. Journal of Personality and Social Psychology, 96, 933.

Jones, C. R., Olson, M. A., \& Fazio, R. H. (2010). Evaluative conditioning: The "how" question. In Advances in experimental social psychology (Vol. 43, pp. 205-255). Academic Press.

Kamin, L. J. (1969). Predictability, suprise, attention and conditioning. In CAMPBELL, B. and CHURCH, R. (Eds), Punishment and Aversive Behavior. New York: AppletonCentury-Crofts.

Kardes, F. R., \& Kalyanaram, G. (1992). Order-of-entry effects on consumer memory and judgment: An information integration perspective. Journal of Marketing Research, 29, 343-357.

Kardes, F. R., \& Sanbonmatsu, D. M. (1993). Direction of comparison, expected feature correlation, and the set-size effect in preference judgment. Journal of Consumer Psychology, 2, 3954.

Kim, H. W., \& Kankanhalli, A. (2009). Investigating user resistance to information systems implementation: A status quo bias perspective. MIS quarterly, 567-582.

Koch, A., Alves, H., Krüger, T., \& Unkelbach, C. (2016). A general valence asymmetry in similarity: Good is more alike than bad. Journal of Experimental Psychology: Learning, Memory, and Cognition, 42, 1171. 
Koranyi, N., Gast, A., \& Rothermund, K. (2013). "Although Quite Nice, I Was Somehow Not Attracted by That Person" Attitudes Toward Romantically Committed Opposite-Sex Others Are Immune to Positive Evaluative Conditioning. Social Psychological and Personality Science, 4, 403-410.

Konkle, T., Brady, T. F., Alvarez, G. A., \& Oliva, A. (2010). Conceptual distinctiveness supports detailed visual long-term memory for real-world objects. Journal of experimental Psychology: General, 139, 558.

Kruschke, J. K. (2001). Toward a unified model of attention in associative learning. Journal of Mathematical Psychology, 45, 812-863.

Kruschke, J. K. (2003). Attention in learning. Current Directions in Psychological Science, 12, 171-175.

Kruschke, J. K., \& Blair, N. J. (2000). Blocking and backward blocking involve learned inattention. Psychonomic Bulletin \& Review, 7, 636-645.

Lang, P. J., Bradley, M. M., \& Cuthbert, B. N. (1997). International affective picture system (IAPS): Technical manual and affective ratings. NIMH Center for the Study of Emotion and Attention, 1, 39-58.

Lebens, H., Roefs, A., Martijn, C., Houben, K., Nederkoorn, C., \& Jansen, A. (2011). Making implicit measures of associations with snack foods more negative through evaluative conditioning. Eating behaviors, 12, 249-253.

Leising, D., Ostrovski, O., \& Zimmermann, J. (2013). “Are we talking about the same person here?" Interrater agreement in judgments of personality varies dramatically with how much the perceivers like the targets. Social Psychological and Personality Science, 4, 468-474.

Levey, A. B., \& Martin, I. (1975). Classical conditioning of human 'evaluative' responses. Behaviour Research and Therapy, 13, 221-226.

Mackintosh, N. J. (1975). A theory of attention: variations in the associability of stimuli with reinforcement. Psychological Review, 82, 276.

Mackintosh, N. J. (1976). Overshadowing and stimulus intensity. Animal Learning \& Behavior, 4, 186-192.

March, D. S., Olson, M. A., \& Fazio, R. H. (2018). The implicit misattribution model of evaluative conditioning. Social Psychological Bulletin, 13, e27574.

Martijn, C., Sheeran, P., Wesseldijk, L. W., Merrick, H., Webb, T. L., Roefs, A., \& Jansen, A. (2013). Evaluative conditioning makes slim models less desirable as standards for comparison and increases body satisfaction. Health Psychology, 32(4), 433.

McGill, A. L. (1989). Context effects in judgments of causation. Journal of Personality and Social Psychology, 57, 189.

Mitchell, C. J., De Houwer, J., \& Lovibond, P. F. (2009). The propositional nature of human associative learning. Behavioral and Brain Sciences, 32, 183-198.

Moran, T., Bar-Anan, Y., \& Nosek, B. A. (2015). Processing goals moderate the effect of co-occurrence on automatic evaluation. Journal of Experimental Social Psychology, 60, 157162.

Mrkva, K., \& Van Boven, L. (in press). Salience theory of mere exposure: Relative exposure increases liking, extremity, and emotional intensity. Journal of Personality and Social Psychology.

Olson, M. A., \& Fazio, R. H. (2006). Reducing automatically activated racial prejudice through implicit evaluative conditioning. Personality and Social Psychology Bulletin, 32, 421-433.
Pavlov, I. P. (1927). Conditioned reflexes: an investigation of the physiological activity of the cerebral cortex. Oxford, England: Oxford Univ. Press.

Perloff, L. S., \& Fetzer, B. K. (1986). Self-other judgments and perceived vulnerability to victimization. Journal of Personality and Social Psychology, 50, 502.

Pleyers, G., Corneille, O., Yzerbyt, V., \& Luminet, O. (2009). Evaluative conditioning may incur attentional costs. Journal of Experimental Psychology: Animal Behavior Processes, 35, 279.

Pryor, J. B., Reeder, G. D., \& Monroe, A. E. (2012). The infection of bad company: Stigma by association. Journal of Personality and Social Psychology, 102, 224.

Randich, A., \& LoLordo, V. M. (1979). Associative and nonassociative theories of the UCS preexposure phenomenon: implications for Pavlovian conditioning. Psychological Bulletin, 86, 523.

Rescorla, R. A., \& Wagner, A. R. (1972). A theory of Pavlovian conditioning: Variations in the effectiveness of reinforcement and nonreinforcement. In A. H. Black \& W. F. Prokasy (Eds.), Classical conditioning II (pp. 64-99). New York: AppletonCentury-Crofts

Samuelson, W., \& Zeckhauser, R. (1988). Status quo bias in decision making. Journal of Risk and Uncertainty, 1, 7-59.

Sanbonmatsu, D. M., Kardes, F. R., \& Gibson, B. D. (1991). The role of attribute knowledge and overall evaluations in comparative judgment. Organizational Behavior and Human Decision Processes, 48, 131-146.

Savage, L. J. (1954): The Foundations of Statistics. New York (2nd ed. 1972): John Wiley \& Sons; New York: Dover Publications.

Schienle, A., Stark, R., \& Vaitl, D. (2001). Evaluative conditioning: A possible explanation for the acquisition of disgust responses? Learning and Motivation, 32, 65-83.

Schlenkermann, R. S. (2007). Negative evaluative conditioning of implicit smoking attitudes as an avenue toward cessation. ProQuest.

Sears, D. O. (1983). The person-positivity bias. Journal of Personality and Social Psychology, 44, 233.

Sherman, J. W., Kruschke, J. K., Sherman, S. J., Percy, E. J., Petrocelli, J. V., \& Conrey, F. R. (2009). Attentional processes in stereotype formation: A common model for category accentuation and illusory correlation. Journal of Personality and Social Psychology, 96, 305.

Stahl, C., Unkelbach, C., \& Corneille, O. (2009). On the respective contributions of awareness of unconditioned stimulus valence and unconditioned stimulus identity in attitude formation through evaluative conditioning. Journal of Personality and Social Psychology, 97, 404.

Sherman, S. J., Houston, D. A., \& Eddy, D. (1999). Cancellation and focus: A feature-matching model of choice. European Review of Social Psychology, 10, 169-197.

Stahl, C., \& Aust, F. (2018). Evaluative conditioning as memorybased judgment. Social Psychological Bulletin, 13, e28589.

Stahl, C., \& Unkelbach, C. (2009). Evaluative learning with single versus multiple USs: The role of contingency awareness. Journal of Experimental Psychology: Animal Behavior Processes, 35, 286-291.

Stahl, C., Unkelbach, C., \& Corneille, O. (2009). On the respective contributions of awareness of unconditioned stimulus valence and unconditioned stimulus identity in attitude formation through evaluative conditioning. Journal of Personality and Social Psychology, 97, 404. 
Strick, M., Van Baaren, R. B., Holland, R. W., \& Van Knippenberg, A. (2009). Humor in advertisements enhances product liking by mere association. Journal of Experimental Psychology: Applied, 15, 35.

Stuart, E. W., Shimp, T. A., \& Engle, R. W. (1987). Classical conditioning of consumer attitudes: Four experiments in an advertising context. Journal of Consumer Research, 14, 334349.

Sweldens, S., Van Osselaer, S. M., \& Janiszewski, C. (2010). Evaluative conditioning procedures and the resilience of conditioned brand attitudes. Journal of Consumer Research, 37, 473-489.

Tingley, D., Yamamoto, T., Hirose, K., Keele, L., \& Imai, K. (2014). Mediation: R package for causal mediation analysis.

Tversky, A. (1977). Features of similarity. Psychological Review, 84, 327.

Tversky, A., \& Gati, I. (1982). Similarity, separability, and the triangle inequality. Psychological Review, 89, 123.

Unkelbach, C. (2012). Positivity advantages in social information processing. Social and Personality Psychology Compass, 6, 8394.

Unkelbach, C., \& Fiedler, K. (2016). Contrastive CS-US relations reverse evaluative conditioning effects. Social Cognition, 34, 413-434.

Unkelbach, C., \& Högden, F. (2019). Why does George Clooney make coffee sexy? The case for Attribute Conditioning. Current Directions in Psychological Science, 28, 540-546.

Unkelbach, C., Koch, A., \& Alves, H. (2019). The Evaluative Information Ecology: On the frequency and diversity of "good" and "bad". European Review of Social Psychology, 30, 216-270.

Unkelbach, C., \& Memmert, D. (2014). Serial-position effects in evaluative judgments. Current Directions in Psychological Science, 23, 195-200.

Vogel.T. \& Wänke, M. (2016). Attitudes and Attitude Change. 2nd ed. Hove: (UK) Psychology Press.

von Neumann, J., \& Morgenstern, O. (1947). Theory of games and economic behavior (2nd ed.). Princeton: Princeton University Press.

Walther, E., Nagengast, B., Trasseli, C. (2005). Evaluative condition in social psychology: Facts and speculations. Cognition \& Emotion, 19,175-196.
Walther, E., Ebert, I., \& Meinerling, K. (2011). Does cue competition reduce conditioned liking of brands and products? Psychology \& Marketing, 28, 520-538.

Walther, E., \& Grigoriadis, S. (2004). Why sad people like shoes better: The influence of mood on the evaluative conditioning of consumer attitudes. Psychology \& Marketing, 21, 755-773.

Wennekers, A. M., Holland, R. W., Wigboldus, D. H., \& Knippenberg, A. V. (2012). First see, then nod: The role of temporal contiguity in embodied evaluative conditioning of social attitudes. Social Psychological and Personality Science, 3, 455-461.

Wood, D., \& Furr, R. M. (2016). The correlates of similarity estimates are often misleadingly positive: The nature and scope of the problem, and some solutions. Personality and Social Psychology Review, 20, 79-99.

Wyer, R. S. (1974). Cognitive organization and change: An information-processing approach. Hillsdale, NJ: Lawrence Erlbaum Associates.

${ }^{1}$ This task was originally meant to measure participants' memory for distinct and redundant pairings. However, the data is not presented here because as correctly pointed out by an anonymous reviewer, the set-up of this task did not allow any valid conclusions regarding participants' memory performance. Participants were presented with each of the four brands, along with all 10 US pictures (two redundant and eight distinct), and they were asked to indicate which of these US pictures were presented with each respective brand. A problem if this task was that the distinct vs. redundant status of US pictures was confounded with their overall number. Because there were eight different distinct US pictures, but only two different redundant US pictures, memory accuracy for distinct and redundant pictures naturally differs and these differences are difficult to interpret.

${ }^{2}$ Experiment 4 included the same memory task as Experiment 3. We do not report the data here, but we participants' responses can be found in the data set which is available online (https://osf.io/eujs6/?view_only=3edac6edbdb84accb481ddfe6154 901d). 